\title{
Transport of Po Valley aerosol pollution to the northwestern Alps - Part 1: Phenomenology
}

\author{
Henri Diémoz ${ }^{1}$, Francesca Barnaba ${ }^{2}$, Tiziana Magri $^{1}$, Giordano Pession ${ }^{1}$, Davide Dionisi ${ }^{2}$, Sara Pittavino $^{1}$, \\ Ivan K. F. Tombolato ${ }^{1}$, Monica Campanelli ${ }^{2}$, Lara Sofia Della Ceca ${ }^{3}$, Maxime Hervo ${ }^{4}$, Luca Di Liberto ${ }^{2}$, \\ Luca Ferrero ${ }^{5}$, and Gian Paolo Gobbi ${ }^{2}$ \\ ${ }^{1}$ ARPA Valle d'Aosta, Saint-Christophe, Italy \\ ${ }^{2}$ Institute of Atmospheric Science and Climate, ISAC-CNR, Rome, Italy \\ ${ }^{3}$ Instituto de Física Rosario, Rosario, Argentina \\ ${ }^{4}$ MeteoSwiss, Payerne, Switzerland \\ ${ }^{5}$ GEMMA and POLARIS research centres, Department of Earth and Environmental Sciences, \\ University of Milano-Bicocca, Milan, Italy
}

Correspondence: Henri Diémoz (h.diemoz@arpa.vda.it)

Received: 10 September 2018 - Discussion started: 24 October 2018

Revised: 30 January 2019 - Accepted: 31 January 2019 - Published: 11 March 2019

\begin{abstract}
Mountainous regions are often considered pristine environments; however they can be affected by pollutants emitted in more populated and industrialised areas, transported by regional winds. Based on experimental evidence, further supported by modelling tools, here we demonstrate and quantify the impact of air masses transported from the Po Valley, a European atmospheric pollution hotspot, to the northwestern Alps. This is achieved through a detailed investigation of the phenomenology of near-range (a few hundred kilometres), trans-regional transport, exploiting synergies of multi-sensor observations mainly focussed on particulate matter. The explored dataset includes vertically resolved data from atmospheric profiling techniques (automated lidar ceilometers, ALCs), vertically integrated aerosol properties from ground (sun photometer) and space, and in situ measurements $\left(\mathrm{PM}_{10}\right.$ and $\mathrm{PM}_{2.5}$, relevant chemical analyses, and aerosol size distribution). During the frequent advection episodes from the Po basin, all the physical quantities observed by the instrumental setup are found to significantly increase: the scattering ratio from ALC reaches values $>30$, aerosol optical depth (AOD) triples, surface $\mathrm{PM}_{10}$ reaches concentrations $>100 \mathrm{\mu g} \mathrm{m}^{-3}$ even in rural areas, and contributions to $\mathrm{PM}_{10}$ by secondary inorganic compounds such as nitrate, ammonium, and sulfate increase up to $28 \%, 8 \%$, and $17 \%$, respectively. Results also indicate that the aerosol advected from the Po Valley is hygroscopic, smaller in size,
\end{abstract}

and less light-absorbing compared to the aerosol type locally emitted in the northwestern Italian Alps. In this work, the phenomenon is exemplified through detailed analysis and discussion of three case studies, selected for their clarity and relevance within the wider dataset, the latter being fully exploited in a companion paper quantifying the impact of this phenomenology over the long-term (Diémoz et al., 2019). For the three case studies investigated, a high-resolution numerical weather prediction model (COSMO) and a Lagrangian tool (LAGRANTO) are employed to understand the meteorological mechanisms favouring transport and to demonstrate the Po Valley origin of the air masses. In addition, a chemical transport model (FARM) is used to further support the observations and to partition the contributions of local and non-local sources. Results show that the simulations are important to the understanding of the phenomenon under investigation. However, in quantitative terms, modelled $\mathrm{PM}_{10}$ concentrations are 4-5 times lower than the ones retrieved from the ALC and maxima are anticipated in time by $6-7 \mathrm{~h}$. Underestimated concentrations are likely mainly due to deficiencies in the emission inventory and to water uptake of the advected particles not fully reproduced by FARM, while timing mismatches are likely an effect of suboptimal simulation of up-valley and down-valley winds by COSMO. The advected aerosol is shown to remarkably degrade the air quality of the Alpine region, with potential negative effects 
on human health, climate, and ecosystems, as well as on the touristic development of the investigated area. The findings of the present study could also help design mitigation strategies at the trans-regional scale in the Po basin and suggest an observation-based approach to evaluate the outcome of their implementation.

\section{Introduction}

In mountainous regions, mutual exchanges between the valley atmosphere and the nearby plains have been recognised and studied for more than a century (e.g. Thyer, 1966, and references therein). Notably, daytime up-valley (nighttime down-valley) flows systematically develop as a result of faster heating (cooling) of mountain valleys compared to the foreland (Rampanelli et al., 2004; Serafin and Zardi, 2010; Schmidli, 2013; Wagner et al., 2014), and hence manifest on a very regular basis, especially during fair-weather days (nights) with weak synoptic circulation (Borghi and Giuliacci, 1980; Tampieri et al., 1981). The plain-to-mountain circulation regime conveys mass, heat, and moisture within the planetary boundary layer (PBL), thus contributing to horizontal mixing on the mesoscale (Weissmann et al., 2005). Additionally, air parcels can be lifted by convection above the ridges and transported to the free troposphere, which favours air mass exchange in the vertical direction (Henne et al., 2004; Gohm et al., 2009; Schnitzhofer et al., 2009; Lang et al., 2015).

Thermally driven wind systems are observed in mountainous regions throughout the world (e.g. Cong et al., 2015; Collaud Coen et al., 2018; Dhungel et al., 2018). The European Alps have been the ideal scenario for such kinds of studies, owing to their rugged shape, forming hundreds of main and tributary valleys, and large surrounding plains with strong emission sources, the most significant being in the Po basin. Indeed, this vast region, which includes a large portion of northern Italy, is one of the most densely populated (more than 20 million people and a population density of 414 inhabitants per square kilometre, WMO, 2012), industrialised, and thus polluted areas in Europe (Chu et al., 2003; Van Donkelaar et al., 2010; Fuzzi et al., 2015; EMEP, 2016). The valley morphology exacerbates the air quality. In fact, heavy emissions from productive activities as well as from vehicular traffic and residential heating are often trapped within the Po basin due to its characteristic topography strongly limiting the dispersion of pollutants, with the Alpine chain and the Apennines enclosing the plain on its northern, western, and southern sides. As a consequence, the Po basin is one of the European hotspots suffering from premature mortality associated with atmospheric pollution (EEA, 2015). In spite of the improvements in the last decades (e.g. Bigi and Ghermandi, 2016), the air quality in the Po Valley is still far from the standards established by the European Commission (EU
Commission, 2008) and exceedances of these standards are expected to continue in the next years (Belis et al., 2017; Caserini et al., 2017; EEA, 2017; Guariso and Volta, 2017).

Both theoretical studies and experimental campaigns demonstrated that transboundary transport of several kinds of pollutants from the Po basin affects pre-Alpine areas (Dosio et al., 2002; Neftel et al., 2002; Mélin and Zibordi, 2005), the Italian Alpine valleys (Nyeki et al., 2002; Larsen et al., 2012; Ferrero et al., 2014), other Italian regions (Cristofanelli et al., 2009; Carbone et al., 2014; Moroni et al., 2015), and even neighbouring countries (e.g. Wotawa et al., 2000; Finardi et al., 2014). Over the impacted areas, a correct partitioning between local and non-local sources is therefore necessary to (1) correctly interpret the exceedances of air quality limits and (2) develop joint efforts and large-scale mitigation strategies (WMO, 2012) to reduce the frequency and impact of pollution episodes on citizen health (Straif et al., 2013; WHO, 2016; Zhang et al., 2017), climate (Clerici and Mélin, 2008; Lau et al., 2010; Zeng et al., 2015), and ecosystems (Carslaw et al., 2010; Bourgeois et al., 2018; Burkhardt et al., 2018). As an additional important aspect, in mountainous regions, pollution layers undermine the visual quality of the landscape (e.g. Fig. 1a) and thus touristic attractiveness, with obvious economic implications (de Freitas, 2003).

In the present study, we aim at illustrating and deeply investigating the phenomenology of aerosol transport events to the northwestern Alpine region through a detailed analysis and discussion of specifically selected case studies. The impacts of this phenomenon over the long-term will be quantified in a companion paper (Diémoz et al., 2019).

In fact, several previous field campaigns investigated the atmospheric composition and transport mechanisms in the eastern and central part of the Po Valley (Nyeki et al., 2002; Barnaba et al., 2007; Ferrero et al., 2010; Larsen et al., 2012; Decesari et al., 2014; Khan et al., 2016; Rosati et al., 2016; Cugerone et al., 2018), but very few studies are available on the westernmost side of the basin (Anfossi et al., 1988; Mercalli et al., 2003; Manara et al., 2018). Earlier evidence of possible advection of pollutants from the Po basin to the northwestern Alps was collected in the framework of two intensive 4-day-long campaigns performed between 2000 and 2001 (Agnesod et al., 2003). At that time, an equipped aircraft flew during anticyclonic conditions with weak synoptic circulation in order to assess the effects of the local winds on the air quality in the Alpine valleys close to Mont Blanc (in Italy, France, and Switzerland). The experiment was focussed on ozone measurements and its precursors; however aerosol concentrations were additionally measured. Capping inversions limiting the development of the mixing layer, vertical transport of pollutants along the valley slopes, and the ozone-polluted residual layer aloft (entrained into the mixing layer during the next day) were the most interesting phenomena explored by that study. Advection from the Po Valley with thermally driven flows was hypothesised to be the main factor contributing to the high ozone concentrations found 




(a)



(b)

Figure 1. (a) Panoramic view of the main valley over the Aosta-Saint-Christophe station during a pollution advection event. The picture was taken from Croce di Fana (2200 m a.s.1., Quart village, $6 \mathrm{~km}$ northeast of Aosta-Saint-Christophe) on 21 October 2017. On that day, the advected layer of aerosol - visible in the picture as a hazy layer - reached an altitude of about 2000 m a.s.1. Photo kindly provided by Corrado Cometto. (b) Image of the Po Valley from the MODIS Aqua radiometer (corrected reflectance, true colour) only a few days before the picture in (a) was taken (18 October; https://worldview.earthdata.nasa.gov, last access: 28 February 2019). The satellite view clearly shows that the hazy aerosol-rich layer from the Po basin is starting to pour out into the Alpine valleys. The pink marker identifies the Aosta-Saint-Christophe site.

in the elevated layers. Although this result was supported by measurements of carbon monoxide, ambient particulate matter (PM), and relative humidity (RH), the short duration of the campaign could not allow exclusion of other effects. More recently, Diémoz et al. (2014a) analysed a 1-year-long time series of columnar aerosol optical properties measured by a sun-sky photometer in the same area and found that the heaviest burden of particles did not come from the largest urban settlement in the Aosta Valley, but rather from outside the region, namely from the Po basin.

The present research exploits a multi-technique approach, combining a large set of measurements with modelling tools in order to answer the following scientific questions still lacking a comprehensive understanding:

1. What is the origin of the aerosol layers detected in the northwestern Alps?
2. What conditions are favourable to the aerosol flow into the valley?

3. How do the advected aerosol layers evolve in both altitude and time?

4. What is the impact of the transported aerosol on PM surface concentrations and chemical composition?

5. Are the current chemical transport models able to reproduce and explain the observations at the ground and along the vertical profile?

Though referring to the location object of the study, these questions are of more general interest, as several regions of the world are characterised by basin valleys surrounded by mountains. Hence, the role of pollution advection, their vertical behaviour and the final impact at ground level is a mat- 


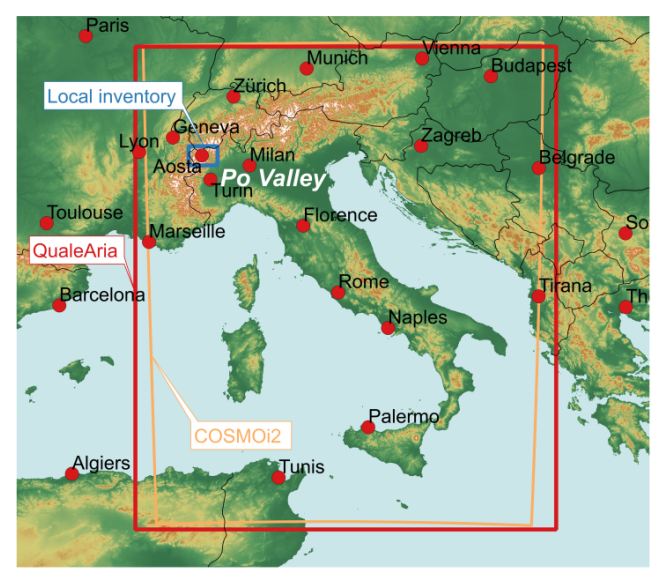

(a)

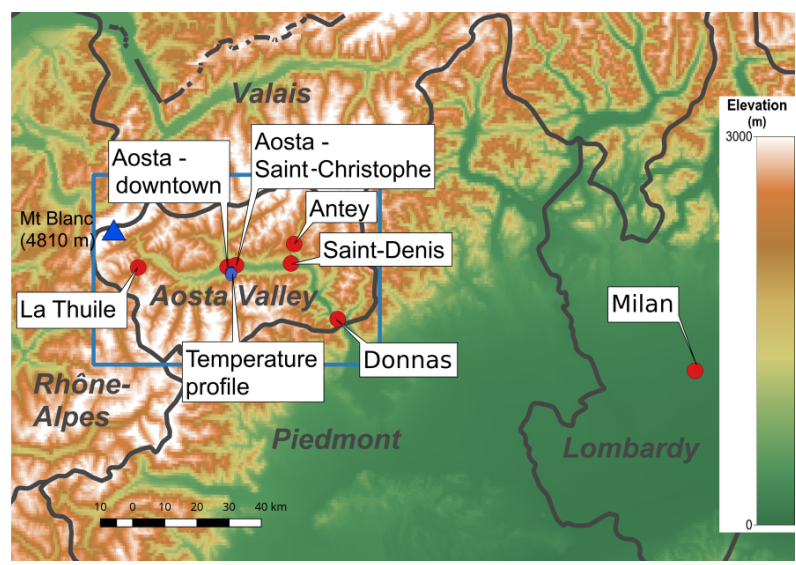

(b)

Figure 2. (a) Elevation map of Italy, showing the position of the investigated Alpine region and the geographical domains of (1) the numerical weather prediction model (COSMO-I2, orange box), (2) the national emission inventory (QualeAria, red box), and (3) the local inventory of the Aosta Valley (blue box). (b) Zoom over the Aosta Valley and northwestern Italy, with location of the measurement stations. The blue box corresponds to the geographic domain of the local inventory as in panel (a). The elevation (colour) scale is the same for both figures.

ter of global interest (De Wekker et al., 2018; Lehner and Rotach, 2018; Serafin et al., 2018).

The paper is organised as follows: the investigated area is presented in Sect. 2, while Sect. 3 describes both the experimental (Sect. 3.1) and the modelling (Sect. 3.2) approach used. Results (Sect. 4) are presented by addressing specific case studies to exemplify the advection of polluted aerosolrich air masses and comparing them to the simulations. Conclusions are drawn in Sect. 5.

\section{Investigated area and experimental sites}

This study is mainly focussed on the Aosta Valley, the smallest Italian administrative region (130000 inhabitants, Fig. 2). It is about $80 \mathrm{~km}$ by $40 \mathrm{~km}$ wide and is located on the northwestern side of the Alps, not far from the two major urban settlements and industrial areas of the Po Valley, i.e. Turin $(80 \mathrm{~km})$ and Milan $(150 \mathrm{~km})$. The region is characterised by a complex topography, typical of the Alpine valleys. Its surface elevation varies from 300 to $4800 \mathrm{~m}$ a.s.l. (average altitude $>2000 \mathrm{~m}$ a.s.l.), with several tributary valleys starting from the main valley. The latter connects Mont Blanc (at the border with France, Fig. 2b) to the Piedmont region through a $90 \mathrm{~km}$ long directrix, approximately divisible into three segments with NW-SE, W-E, and NW-SE directions. This main valley is narrower at both ends (with a minimum width of a few hundred metres) and widens in correspondence with Aosta city, the largest urban settlement of the region (about 35000 inhabitants). The complex topography triggers several meteorological phenomena typical of mountain valleys, such as wind channelling along the main valley, thermally driven winds from the plain to the mountains (and vice versa), rainshadow (foehn) winds, and temperature inversions. The latter are very frequent during wintertime, occurring about $50 \%$ of the time (Vuillermoz et al., 2013). Not surprisingly, these dynamics strongly affect the dispersion of pollutants and the air quality in the lowest atmospheric layers.

Data from several measuring sites in the Aosta Valley are used in this work (Fig. 2b). Most of the instruments employed (Sect. 3.1) are operated at the two observatories run by the regional environment protection agency (ARPA) in Aosta: Aosta-Saint-Christophe and Aosta-downtown. The Aosta-Saint-Christophe station (WIGOS ID 0-380-5-1, $45.7^{\circ} \mathrm{N}, 7.4^{\circ} \mathrm{E}, 560 \mathrm{~m}$ a.s.1.) is located in a large flat area with a wide field of view, at the bottom of the main valley, about $2.5 \mathrm{~km}$ east of Aosta-downtown. The site is in a semirural context, partially influenced by vehicular traffic and anthropogenic activities from the city, such as domestic heating and industry. The experimental setup at this site includes an automated lidar ceilometer (ALC) for the operational monitoring of the aerosol profile (Dionisi et al., 2018), a POM-02 sun photometer for the retrieval of column aerosol properties and water vapour (Diémoz et al., 2014a; Campanelli et al., 2018), and a Fidas 200s optical particle counter (OPC) for the surface aerosol size distribution, in addition to instruments measuring solar radiation and trace gases (Diémoz et al., 2011, 2014b; Siani et al., 2013, 2018; Federico et al., 2017). Aosta-downtown (580 m a.s.1.) is an urban background site. This station is equipped with samplers for continuous monitoring of atmospheric pollution, mainly coming from car traffic, domestic heating, and a steel mill located south of the city. To provide an idea of the aerosol load in Aostadowntown, the annual averages of $\mathrm{PM}_{10}$ and $\mathrm{PM}_{2.5}$ concentrations calculated for the last 3 years of measurements (2015-2017) range between 18 and 21 and between 11 and $12 \mu \mathrm{g} \mathrm{m}^{-3}$, respectively. Despite these low average concen- 
trations, daily $\mathrm{PM}_{10}$ exceedance episodes with maxima of up to about $100 \mathrm{\mu g} \mathrm{m}^{-3}$ can be observed, their occurrence strongly depending on the encountered meteorological conditions (five exceedance episodes in 2016, 13 in 2015, and 17 in 2017). Thus, there is the need to unravel their behaviour and the role played by regional transport from most polluted areas. Additional measurements used here were performed at the more elevated sites of La Thuile ( $1640 \mathrm{~m}$ a.s.l.), SaintDenis ( $840 \mathrm{~m}$ a.s.l.), and Antey (1040 m a.s.1.) and at Donnas, a low-altitude site ( $316 \mathrm{~m}$ a.s.l., Fig. 2b) close to the border with the Piedmont region, at the entrance of the Aosta Valley. La Thuile is a remote mountain site in a tributary valley hosting a meteorological and air quality station managed by ARPA. Similarly, a weather station is operated in the village of Saint-Denis by the regional meteorological bureau. Antey is a further small village in a tributary valley where an ARPA mobile laboratory was temporary operated. Finally, the Donnas station is located in a rural area, only partially influenced by traffic and agricultural local activities, such as burning of agricultural residuals. However, due to its proximity to the Po basin, it is expected to be heavily influenced by pollution from the plain.

As the vertical dimension is important in this investigation, we also used measurements from an ALC operating in Milan (Fig. 2), this being representative of the contrasting conditions within the Po Valley. The system is located on the U9-building ( $45.5^{\circ} \mathrm{N}, 9.2^{\circ} \mathrm{E}, 132 \mathrm{~m}$ a.s.l.) of the University of Milano-Bicocca, in an urban background area northeast of the city centre. A full description of the site and measurements is reported in Ferrero et al. (2018).

\section{Methods}

\subsection{Measurements}

The experimental setup used in this work includes vertically resolved measurements from ALCs (Sect. 3.1.1), vertically integrated (columnar) aerosol measurements from both ground (Sect. 3.1.2) and space (Sect. 3.1.3), and in situ measurements of aerosol concentration and composition (Sect. 3.1.4-3.1.5), complemented by ancillary gas-phase pollutants and meteorological measurements (Sect. 3.1.6). Table 1 summarises the instruments used throughout this study at their respective measuring stations.

\subsubsection{Automated lidar ceilometers}

Vertical profiles of air constituents are particularly useful in identifying transport of pollutants of non-local origin. However, the profiling capability of the Italian regional environment protection agencies is still scarce. Over the Po basin, continuous monitoring of the atmospheric composition along the vertical profile is lacking and information at different altitudes is mostly available for short periods and during specific dedicated field campaigns (e.g. Barnaba et al., 2007; Osborne et al., 2007; Raut and Chazette, 2009; Barnaba et al., 2010; Ferrero et al., 2014; Curci et al., 2015; Rosati et al., 2016; Bucci et al., 2018).

Light detection and ranging (lidar) instruments permit us to resolve the vertical distribution of particles. The recent technological and data-processing advances (Wiegner and Geiß, 2012), and commercialisation, of simple lidar systems with operational capabilities allow to use this kind of system in monitoring (24/7) mode and in wide networks. In the present study, we employ two commercially available ALCs (CHM15k-Nimbus, manufactured by Lufft GmbH, and formerly by Jenoptik ESW), which have been operating since 2015 at the Aosta-Saint-Christophe observatory and in Milan. Both ALCs are part of the Italian ALICEnet (http://www.alice-net.eu/, last access: 28 February 2019) and the European E-PROFILE (https://ceilometer.e-profile. eu/profileview, last access: 28 February 2019) networks. They allow for continuous vertical profiling of the radiation emitted by a single-wavelength $(1064 \mathrm{~nm})$ pulsed laser (Nd:YAG; $6.5-7 \mathrm{kHz} ; 8 \mu \mathrm{J}_{\text {pulse }}{ }^{-1}$ ) and backscattered by the atmosphere. At the operating wavelength, the backscatter is mainly dominated by aerosols and clouds in the atmosphere, whereas interference by water vapour has been estimated to be negligible (Wiegner and Gasteiger, 2015). The systems enable a typical temporal resolution of $15 \mathrm{~s}$ (integration time) and a vertical resolution of $15 \mathrm{~m}$, up to $15 \mathrm{~km}$ above the ground. The main limitations of the instruments are (1) the need for corrections in the lowermost levels and a (2) blind view above thick clouds. (1) In the lowermost levels, the field of view $(0.45 \mathrm{mrad})$ of the receiver is only partially overlapped with the laser beam ( $90 \%$ overlap is achieved at about $700 \mathrm{~m}$ ); therefore, an overlapping correction function is needed to correct the signal. This was provided by the manufacturer. (2) Thick clouds cause saturation in the detector signal (an avalanche photodiode operated in photocounting mode), followed by complete signal extinction. Thus, the attenuated backscatter above the cloud ceiling is not considered (nor plotted) in this study. The ALC firmwares used so far (versions 0.730-0.743 for Aosta-SaintChristophe and 0.730 for Milan) provide the background-, overlap-, and range-corrected attenuated backscatter (RCS) in terms of instrumental raw counts, i.e.

$\operatorname{RCS}(z, t)=\frac{(P(z, t)-B(t)) z^{2}}{O(z)}$,

where $P(z, t)$ is the signal intensity (raw counts) backscattered from a specific distance $(z)$ and measured at ground, $B(t)$ the time-varying background baseline, and $O(z)$ the overlap function. To express the backscatter coefficient in SI units and make the results comparable with other similar instruments, a calibration factor $\left(C_{\mathrm{L}}\right)$ must be assessed, so that

$\frac{\operatorname{RCS}(z, t)}{C_{\mathrm{L}}}=\beta_{\mathrm{att}}(z, t)=\beta_{\mathrm{T}}(z, t) e^{-2 \int_{z_{\min }}^{z} \alpha_{\mathrm{T}}\left(z^{\prime}, t\right) \mathrm{d} z^{\prime}}$, 
Table 1. Observation sites, measurements, and instruments employed in this study.

\begin{tabular}{|c|c|c|c|c|}
\hline Station & $\begin{array}{l}\text { Elevation } \\
(\mathrm{m} \text { a.s.l. })\end{array}$ & Measurement & Instrument & $\begin{array}{l}\text { Data } \\
\text { availability }\end{array}$ \\
\hline \multirow[t]{3}{*}{$\begin{array}{l}\text { Aosta-Saint-Christophe } \\
\text { (ARPA observatory) }\end{array}$} & 560 & $\begin{array}{l}\text { Vertical profile of attenuated backscat- } \\
\text { ter and derived products }\end{array}$ & CHM15k Nimbus ceilometer & 2015-now \\
\hline & & Aerosol columnar properties & POM-02 sun-sky radiometer & 2012-now ${ }^{\mathrm{a}}$ \\
\hline & & Surface particle size distribution & Fidas 200s optical particle counter & 2016-now \\
\hline $\begin{array}{l}\text { Aosta-Saint-Christophe } \\
\text { (weather station) }\end{array}$ & 545 & Standard meteorological parameters & Siap and Micros & 1974-now \\
\hline \multirow[t]{6}{*}{ Aosta-downtown } & 580 & $\mathrm{PM}_{10}$ hourly concentration & TEOM 1400a & 1997-now \\
\hline & & $\mathrm{PM}_{10}$ and $\mathrm{PM}_{2.5}$ daily concentrations & Opsis SM200 & 2011-now \\
\hline & & $\begin{array}{l}\text { Water-soluble anion-cation analyses on } \\
\mathrm{PM}_{10} \text { samples }\end{array}$ & Dionex ion chromatography system & 2017-now \\
\hline & & $\mathrm{EC} / \mathrm{OC}$ analyses on $\mathrm{PM}_{10}$ samples & Sunset thermo-optical analyser & 2017-now ${ }^{b}$ \\
\hline & & $\mathrm{NO}$ and $\mathrm{NO}_{2}$ & Horiba APNA-370 & 1995-now \\
\hline & & Standard meteorological parameters & Vaisala WA15 & 1995-now \\
\hline South mountain slope & $550-1200$ & Temperature and RH profile & HOBO H8 Pro (10 thermometers) & 2006-now \\
\hline \multirow[t]{2}{*}{ La Thuile } & 1640 & $\mathrm{PM}_{10}$ hourly concentration & TEOM $1400 \mathrm{a}$ & 2015-now \\
\hline & & $\mathrm{NO}$ and $\mathrm{NO}_{2}$ & Teledyne API200E & 1997-now \\
\hline Saint-Denis & 840 & Standard meteorological parameters & Siap and Micros & 2002-now \\
\hline Antey & 1040 & $\mathrm{PM}_{10}$ daily concentration & Opsis SM200 & 2017 \\
\hline \multirow[t]{3}{*}{ Donnas } & 316 & $\mathrm{PM}_{10}$ daily concentration & Opsis SM200 & 2010-now \\
\hline & & $\mathrm{NO}$ and $\mathrm{NO}_{2}$ & Teledyne API200E & 1995-now \\
\hline & & Standard meteorological parameters & Micros & 1994-now \\
\hline \multirow[t]{2}{*}{ Milan } & 132 & $\begin{array}{l}\text { Vertical profile of attenuated backscat- } \\
\text { ter and derived products }\end{array}$ & CHM15k Nimbus ceilometer & 2015-now \\
\hline & & Standard meteorological parameters & Vaisala WXT5 & 2012-now \\
\hline
\end{tabular}

a Underwent major maintenance in the second half of 2016 and January 2017. ${ }^{\text {b }}$ Available for 4 days every 10 days.

where $\beta_{\text {att }}$ is the attenuated backscatter coefficient, $\beta_{\mathrm{T}}$ is the total (particles and molecules) backscatter coefficient, and $\alpha_{\mathrm{T}}$ is the total extinction coefficient. $C_{\mathrm{L}}$ is determined during clear-sky time windows of at least $3 \mathrm{~h}$ at night, i.e. when the background radiation is low, using the method (Rayleigh technique) described hereafter. First, the backscatter and extinction profiles are calculated with the Klett-Fernald backward algorithm (Fernald, 1984; Klett, 1985); then $C_{\mathrm{L}}$ is determined by inverting Eq. (2). Once a series of calibration factors has been estimated, the total $\left(\alpha_{\mathrm{T}}, \beta_{\mathrm{T}}\right)$ and particle $\left(\alpha_{\mathrm{p}}\right.$, $\beta_{\mathrm{p}}$ ) extinction and backscatter coefficients are computed for all times and sky conditions using a forward Klett method as described by Wiegner and Geiß (2012).

Usually, the above-mentioned solving techniques are based on an a priori or independent estimate of the lidar ratio (LR, i.e. the ratio $\alpha_{\mathrm{p}} / \beta_{\mathrm{p}}$ ) as a further constraint. In our case, LR is not fixed a priori but rather obtained using specific functional relationships linking $\alpha_{\mathrm{p}}$ to $\beta_{\mathrm{p}}$. Dionisi et al. (2018) demonstrated that this approach, previously proposed and tested on the signal inversion of research-type elastic lidars (e.g. Barnaba and Gobbi, 2001, 2004), provides better retrievals of $\alpha_{\mathrm{p}}$ and $\beta_{\mathrm{p}}$ also from ALCs than using an a priori fixed LR. More specifically, an iterative data inversion scheme is adopted: at the first iteration, LR is set to an initial value of $38 \mathrm{sr}$ (average value from the functional relationships) and a first retrieval of the backscatter coefficient $\beta_{\mathrm{p}}$ is calculated; starting from the second iteration, the calculated backscatter coefficient and the functional relationships are used to determine an altitude-dependent lidar ratio. The loop continues until convergence of the columnintegrated backscatter is reached. The good agreement between the ALC-derived and the sun-photometer-measured aerosol optical depth (AOD, i.e. the integral over altitude of the extinction coefficient) is employed as a validation of the quality of the inversion results (Sect. 4.1.4 and 4.3.5) using these functional relationships, at least in daytime conditions (see also Dionisi et al., 2018, and Figs. S2d and S9e in the Supplement).

For ease of comparison with pristine (aerosol-free) conditions, and with most lidar-based studies, ALC measurements are provided in this study in terms of scattering ratio (SR, e.g. Zuev et al., 2017), i.e.

$\mathrm{SR}=\frac{\beta_{\mathrm{T}}}{\beta_{\mathrm{m}}}=\frac{\beta_{\mathrm{p}}+\beta_{\mathrm{m}}}{\beta_{\mathrm{m}}}$,

where $\beta_{\mathrm{m}}$ is the molecular backscatter coefficient. In the case of pure molecular scattering (no aerosol in the atmosphere), $\mathrm{SR}=1$, while $\mathrm{SR}$ increases with increasing aerosol load. Finally, the high-resolution data from the ALC are downscaled to $75 \mathrm{~m}$ averages over the vertical and $5 \mathrm{~min}$ averages 
over time to increase the signal-to-noise ratio. A first example of the output from the Aosta-Saint-Christophe ALC, in terms of scattering ratio, can be found in Fig. 3a. This image refers to a typical sequence of days (August 2015), characterised by a recurrent increase in the particle backscatter during the afternoon, up to an altitude of more than 2000$3000 \mathrm{~m}$ a.s.l. (the altitude of the surface being $560 \mathrm{~m}$ a.s.l. in Aosta-Saint-Christophe). As we will demonstrate here, this afternoon increase is due to the coupled effect of transport of polluted air masses from the Po basin and aerosol hygroscopic growth (see Sect. 4). Several analogous episodes were recorded in the ALC record since its installation in Aosta-Saint-Christophe. The observation of this recurrent phenomenon was, in fact, the driving motivation for the present research.

In the study, we also convert the ALC-derived backscatter into aerosol volume following Dionisi et al. (2018), thus allowing a direct comparison to more standard air quality metrics (e.g. $\mathrm{PM}_{10}$; this is carried out using a particle density $\rho=1.3 \mathrm{~g} \mathrm{~cm}^{-3}$ independently estimated for the present study by an OPC co-located with the ALC). The expected uncertainties in the retrieval of the aerosol backscatter and extinction coefficients and of the aerosol volume range between $30 \%$ and $40 \%$ (Dionisi et al., 2018).

\subsubsection{Sun photometer}

A POM-02 sun-sky radiometer has operated at the AostaSaint-Christophe observatory since 2012. The radiometer is part of the European ESR-SKYNET network (http://www. euroskyrad.net/, last access: 28 February 2019). The irradiances collected by the POM-02 at 11 wavelengths (315$2200 \mathrm{~nm}$ ) are inverted to retrieve the aerosol optical properties using both the direct sun (SUNRAD.pack algorithm to provide the AOD every 1 min, Estellés et al., 2012) and the almucantar geometries (SKYRAD.pack software version 4.2 to retrieve a complete set of optical and microphysical columnar properties every $10 \mathrm{~min}$, Nakajima et al., 1996). The instrument is calibrated in situ with the improved Langley technique, described by Campanelli et al. (2007) in more detail, and was successfully compared to other reference instruments during a recent international campaign (Kazadzis et al., 2018). The AOD $(\tau)$ from the POM-02 is interpolated to the ALC wavelength $(1064 \mathrm{~nm})$ using the Ångström (1929) relationship, i.e.

$\tau=b \lambda^{-a}$,

where $\lambda$ is the wavelength expressed in micrometres and $a$ and $b$ are the Ångström parameters from the regression. Finally, the Cloud Screening of Sky Radiometer data (CSSR) algorithm by Khatri and Takamura (2009), making use of the short-wave irradiance measurements by a co-located pyranometer, is applied to the POM- 02 series to minimise the residual interference by clouds and to ensure the maximum measurement quality.

\subsubsection{Space-based observations from MODIS}

In this study, we also used satellite data to explore if and how the "local" phenomenon observed in Aosta is detectable over a regional scale. To this purpose, we used AOD data from the Moderate Resolution Imaging Spectroradiometer (MODIS) instrument. The MODIS instrument flies on board the two NASA platforms Terra and Aqua, following a sunsynchronous orbit with overpass times between 10:00 and 13:00 and 13:00 and 16:00 (local time), respectively. Since the MODIS instrument planning phase, specific retrievals have been set up to provide the AOD over ocean and land globally on a daily basis at $10 \mathrm{~km}$ resolution (Kaufman and Tanré, 1998). Constant improvements to the AOD inversion algorithms resulted in a $3 \mathrm{~km}$ resolved standard AOD product (Remer et al., 2013). While such spatial resolutions have been extensively exploited for many regional-scale, aerosolrelated studies, these are yet not sufficient for applications requiring more spatial detail, as in space-based evaluations of air quality within urban areas (e.g. Chudnovsky et al., 2014; Della Ceca et al., 2018) or in conditions of high AOD spatial variability as over mountain regions (e.g. Emili et al., 2011). For our purpose, we therefore used high-resolution $(1 \mathrm{~km})$ AOD data obtained inverting MODIS data with the recently developed algorithm MAIAC (Multi-Angle Implementation of Atmospheric Correction). Full details of this algorithm are thoroughly described in Lyapustin et al. (2011, 2012).

\subsubsection{Optical particle counter}

A Fidas ${ }^{\circledR}$ 200s (Pletscher et al., 2016) OPC operates at the ARPA observatory in Aosta-Saint-Christophe. The spectrometer is based on the analysis of scattered light at $90^{\circ}$ originating from a polychromatic light source (LED). These conditions ensure an accurate calibration curve without ambiguities within the Mie range and allow us to retrieve highresolution spectra (size measurements between 0.18 and $18 \mu \mathrm{m}, 32$ channels decade ${ }^{-1}$ ). Due to the peculiar T-aperture optics of the spectrometer and the simultaneous measurement of signal duration, border zone errors are eliminated. Once the particle size distribution is measured, the instrument algorithm is able to derive the mass concentration for several cutoff diameters (including $\mathrm{PM}_{10}$, i.e. ambient particulate with a diameter of $10 \mu \mathrm{m}$ or less). Though not a direct mass measurement, the PM concentration derived by the instrument obtained the certificate of equivalence to the gravimetric method by TÜV Rheinland Energy GmbH on the basis of a laboratory test and a field test. Moreover, to prevent any site-specific bias, an additional $\mathrm{PM}_{10}$ comparison with the gravimetric technique was organised at Aosta-SaintChristophe and provided satisfactory results (29 days; slope $1.08 \pm 0.04$; intercept $-3.8 \pm 1.4 \mu \mathrm{g} \mathrm{m}^{-3} ; R^{2}=0.96$ ). 


\subsubsection{PM concentration and composition}

Daily averages of PM concentration are recorded by four Opsis SM200 particulate monitor instruments, two in Aostadowntown $\left(\mathrm{PM}_{10}\right.$ and $\mathrm{PM}_{2.5}$ inlets, with sampling fluxes of 1 and $2.3 \mathrm{~m}^{3} \mathrm{~h}^{-1}$, respectively), one installed inside a mobile laboratory, which was parked in Antey $\left(\mathrm{PM}_{10}, 1 \mathrm{~m}^{3} \mathrm{~h}^{-1}\right)$, and one in Donnas $\left(\mathrm{PM}_{10}, 1 \mathrm{~m}^{3} \mathrm{~h}^{-1}\right)$. Moreover, two tapered element oscillating microbalance (TEOM) 1400a monitors (Patashnick and Rupprecht, 1991) are used for continuous measurements of $\mathrm{PM}_{10}$ hourly concentrations at the stations of Aosta-downtown and La Thuile. These instruments do not compensate for mass loss of semi-volatile compounds (Green et al., 2009) and could be insensitive to specific compounds, such as ammonium nitrate (e.g. Charron et al., 2004), which leads to underestimations, especially in the cold season, compared to the SM200. Conversely, overestimations by the TEOM compared to daily averages from the SM200 reference instrument are found in summer and are not fully understood at present. Therefore, TEOM monitors are only employed here for qualitative estimates of short-term variations in the aerosol burden while daily-averaged concentrations will only be taken from the SM200 instruments.

Sampling in Aosta-downtown is complemented with chemical speciation analyses. We employed a Dionex ion chromatography system (AQUION/ICS-1000 modules) for water-soluble anion-cation chemical analyses on daily $\mathrm{PM}_{10}$ samples collected on PTFE-coated glass fiber filters by the Opsis SM200. The experimental setup is based on the CEN/TR 16269:2011 guideline and enables the determination of mass concentrations of the following water-soluble ionic compounds: $\mathrm{Cl}^{-}, \mathrm{NO}_{3}^{-}, \mathrm{SO}_{4}^{2-}, \mathrm{Na}^{+}, \mathrm{NH}_{4}^{+}, \mathrm{K}^{+}, \mathrm{Mg}^{2+}$, and $\mathrm{Ca}^{2+}$. Samples collected on quartz fibre filters by a co-located Micro-PNS automatic low-volume sampling system $\left(10 \mu \mathrm{m}\right.$ cutoff diameter, $\left.2.3 \mathrm{~m}^{3} \mathrm{~h}^{-1}\right)$ are analysed alternatively for elemental/organic carbon (EC/OC, 4/10 days) and for metals (6/10 days; not used in the present study, but discussed by Diémoz et al., 2019). The carbonaceous aerosol mass is determined with a Sunset Laboratory Inc. instrument (Birch and Cary, 1996) on portions of $1 \mathrm{~cm}^{2}$ punches using a thermal-optical transmission (TOT) method with transmission correction for the split point and following the EUSAAR-2 protocol (Cavalli et al., 2010), according to the EN 16909:2017.

\subsubsection{Gas-phase pollutants and meteorological ancillary data}

Standard gas-phase pollutants subject to European regulations are routinely monitored at Aosta-downtown, La Thuile, and Donnas in the frame of the activities of the air quality network. Meteorological parameters, such as temperature, pressure, RH, and surface wind velocity are collected at the stations of Aosta-Saint-Christophe, SaintDenis, and Donnas. Moreover, 10 temperature and RH sen- sors (Hobo H8 Pro) are installed along the north-facing mountain slope south of Aosta, at elevations ranging from 550 to $1200 \mathrm{~m}$ a.s.l. This set of measurements, representing a vertical profile of surface temperature and $\mathrm{RH}$, gives useful information about the thermal inversions in the main valley. For example, pseudo-equivalent potential temperatures (e.g. Freney et al., 2011) at different altitudes can be easily calculated from this dataset, thus providing a rough indication of the vertical extent of the mixed layer (Sect. 4.2.2).

\subsection{Models}

Models are used to interpret and complement the observations. A numerical weather prediction (NWP) model (COSMO, Consortium for Small-scale Modeling, http:// www.cosmo-model.org, last access: 28 February 2019; Sect. 3.2.1) is employed to drive a chemical transport model (FARM, Flexible Air quality Regional Model; Sect. 3.2.2) and a Lagrangian model (LAGRANTO) to retrieve the trajectories of air masses arriving at the experimental site (Sect. 3.2.3).

\subsubsection{Numerical weather prediction model}

COSMO is a non-hydrostatic, fully compressible atmospheric prediction model working on the meso- $\beta$ and meso$\gamma$ scales. A detailed description of the model can be found elsewhere (e.g. Baldauf et al., 2011). The COSMO data are operationally disseminated by the meteorological operative centre - air force meteorological service (COMET) in two different configurations: a lower-resolution $(7 \mathrm{~km}$ horizontal grid and 45-level vertical grid, $72 \mathrm{~h}$ integration) version (COSMO-ME), covering central and southern Europe, and a nudged, higher-resolution version $(2.8 \mathrm{~km}, 65$ vertical levels, 2 runs day ${ }^{-1}$ ), called COSMO-I2 (or COSMO-IT), covering Italy (Fig. 2). Owing to the complex topography of the Aosta Valley and the consequent need to resolve the atmospheric circulation at very small spatial scales, the COSMO-I2 variant is employed in this work.

As an example of the good agreement between COSMO and surface measurements, the average daily cycle of the wind speed and direction from both data sources is exhibited in Fig. S1 in the Supplement. The figure clearly shows the regular development of the plain-mountain winds in the afternoon. The influence of the east-west directrix of the main valley along which the wind is channelled is well represented in both measurements and simulations.

\subsubsection{Chemical transport model}

FARM (v4.7, Gariazzo et al., 2007; Silibello et al., 2008; Cesaroni et al., 2013; Calori et al., 2014) is a threedimensional Eulerian model for simulating the transport, chemical conversion, and deposition of atmospheric pollutants. The FARM source code has been inherited from the Sulfur Transport and dEposition Model (STEM), extensively 
tested and used since the 1980s. FARM can be easily interfaced to most available diagnostic or prognostic NWP models. A turbulence and deposition pre-processor (SURFaceatmosphere interface PROcessor, SURFPRO) computes the 3-D fields of turbulence scaling parameters, eddy diffusivities, and deposition velocities for each species based on an input gridded land-use field and the results of the NWP model (Sokhi et al., 2003). Pollutant emissions from both area and point sources can be simulated by FARM including plume rise calculations. Transformation of chemical species by gas-phase chemistry (more than 200 reactions using the SAPRC-99 chemical scheme as in Carter, 2000), dry removal of pollutants depending on local meteorology and land-use, and wet removal are considered. The AERO3_NEW module, coupled with the gas-phase chemical model and treating primary and secondary particle dynamics and their interactions with gas-phase species, is implemented for the calculation of the aerosol concentration fields, thus accounting for nucleation, condensational growth, and coagulation (Binkowski, 1999). The aerosol size distribution is parametrised using three modes simulated independently: the Aitken mode ( $D<$ $0.1 \mu \mathrm{m})$, the accumulation mode $(0.1 \mu \mathrm{m}<D<2.5 \mu \mathrm{m})$, and the coarse mode $(D>2.5 \mu \mathrm{m})$. $\mathrm{PM}_{2.5}$ is defined as the sum of Aitken and accumulation modes, while $\mathrm{PM}_{10}$ is given by the sum of the three modes. Chemical speciation is performed in the pre-processing phase by the emission manager (EMMA) based on the profiles from the U.S. EPA model SPECIATE (v3.2, 2002; see https://www.epa.gov/ air-emissions-modeling/speciate-version- 45 -through- 40 for more recent versions, last access: 28 February 2019). To simulate hygroscopic growth by aerosols in high- $\mathrm{RH}$ conditions, water uptake by aerosol particles is taken into account based on the ISORROPIA model (Nenes et al., 1998) and added to the $\mathrm{PM}_{10}$ dry mass concentration from FARM. The resulting output species is called $\mathrm{PM}_{10 \mathrm{w}}$ in FARM version 4.7.

The FARM output concentrations are 4-D fields at $1 \mathrm{~km}$ spatial resolution along the horizontal dimensions, 16 different vertical levels (from the surface to $9290 \mathrm{~m}$, corresponding to equally spaced pressure levels), and $1 \mathrm{~h}$ temporal resolution. The $\mathrm{PM}_{10 \mathrm{w}}$ concentration profiles from FARM are extracted at the grid cell corresponding to Aosta-SaintChristophe for comparison with the profiles measured by the ALC. Indeed, since FARM is not able to calculate the aerosol optical properties needed to simulate the backscatter coefficient measured by the ALC, the comparison between the profiles measured by the ALC and estimated by the chemical transport model (CTM) is performed here in terms of mass concentration (by converting the ALC data into $\mathrm{PM}_{10}$; see Sect. 3.1.1).

Supplying a detailed and precise emission inventory to the CTM is crucial to accurately assess the magnitude of the pollutant loads and their variability in both time and space. Additional information regarding the regional emission inventory and the boundary conditions is provided in the Supplement (Sects. S2-S3). The geographic coverage of the regional and the national emission inventories is shown in Fig. 2. Local sources and boundary conditions can be switched on or off for sensitivity analyses.

\subsubsection{Back trajectories}

The publicly available LAGRANTO Lagrangian analysis tool, version 2.0 (Sprenger and Wernli, 2015), is used to numerically integrate the high-resolution 3-D wind fields from COSMO and to determine the origin of the air masses sampled by the ALC over Aosta-Saint-Christophe. The software also enables to trace 3-D and 2-D meteorological fields along each trajectory. In particular, the algorithm was set up to start eight trajectories in a circle of $1 \mathrm{~km}$ around the observing site and at seven different altitudes from the ground to $4000 \mathrm{~m}$ a.s.l., for a total of 56 trajectories for every run. From a 1-year (2016) analysis of the trajectories arriving to the Aosta Valley, it is found that a backward run time of $48 \mathrm{~h}$ is sufficient, on average, to cover most of the domain of the meteorological model. Therefore, we limit the computation to this duration.

\section{Results}

The observed phenomenon is presented through three case studies (August 2015, January 2017, May 2017), chosen for their relevance and clarity. The episodes are also representative of three different atmospheric conditions (seasons) and were observed with slightly different sets of operating instruments (Table 1). The case studies were also selected among those showing long sequences of days characterised by the recurrent appearance of a thick aerosol layer from the ALC, to emphasise the periodicity of the phenomenon. Indeed, as explained in more detail by Diémoz et al. (2019), the elevated aerosol layer can be observed very frequently, i.e. about $50 \%$ of the days, depending on the season.

\subsection{Case study 1: summer (August 2015)}

One of the longest and most notable episodes of unexpected high aerosol loads in the northwestern Alps was registered from 26 August to 3 September 2015, a few months after the ALC installation in Aosta-Saint-Christophe (here we focus on the period 25-31 August, allowing us to show the typical clear conditions before the arrival of the polluted air mass). In those days, a wide anticyclonic area extended from northern Africa to central and eastern Europe. The period is thus representative of fair weather conditions, with only a few cirrus clouds on days 27 and 28 and the absence of strong synoptic flows at ground level, which favoured the regular development of thermally driven winds from the plain to the mountains triggered by temperature and pressure gradients between the valley and the foreground. 



(e)

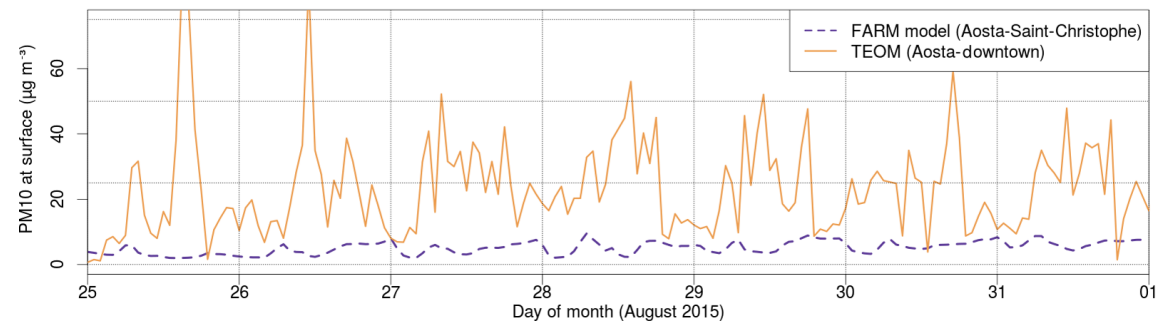

Figure 3. Case study of 25-31 August 2015. (a) Coloured background: vertical profile of scattering ratio from ALC in Aosta-SaintChristophe. The signal above the clouds is plotted as white areas. Arrows: horizontal velocity of the wind measured at the surface (bold, lower arrows) and simulated by COSMO at several elevations (thin arrows). Calm wind (speed $<1 \mathrm{~ms}^{-1}$ ) is not plotted. A reference arrow for a $10 \mathrm{~m} \mathrm{~s}^{-1}$ wind blowing from the south to the north is drawn at the bottom right corner. (b) Vertical profile of relative humidity forecasted by COSMO. (c) Vertical profile of $\mathrm{PM}_{10}$ mass concentration derived from ALC. (d) Mass concentration ( $\left.\mathrm{PM}_{10 \mathrm{w}}\right)$ from FARM. PM concentration from non-local sources is represented by the coloured background (the colour scale is chosen to better show the daily pattern simulated by the model) and the effect of local sources by the contour line, at logarithmic steps (dotted: $0.1 \mu \mathrm{g} \mathrm{m}{ }^{-3}$; dashed, near the surface: $1 \mu \mathrm{g} \mathrm{m}^{-3}$ ). (e) Hourly $\mathrm{PM}_{10}$ (dry) surface concentration from FARM simulations in Aosta-Saint-Christophe and observations in Aosta-downtown, for the purpose of checking if any sudden variation in surface air quality data is noticeable. 


\subsubsection{ALC observations}

A thick aerosol layer is detected by the ALC over the AostaSaint-Christophe observatory from the afternoon of $26 \mathrm{Au}-$ gust (Fig. 3a). Very clear conditions are visible in the low troposphere on 25 August, while the high-altitude layer in the morning of the same day, which is not considered here, is due to smoke transport from North America. The appearance of the PBL layer is clearly noticeable on 26 August as an increase in the backscatter coefficient up to an altitude of $3 \mathrm{~km}$ a.s.l., with scattering ratios $\mathrm{SR} \simeq 4$ at midday (light blue area in the figure) almost doubling ( $\mathrm{SR}>8$, orange yellow) in a few hours. This layer persists during the night, when the SR reaches values above 30. On 27 August, the ALC backscatter is then observed to decrease in the central part of the day and to increase again in the afternoon. This behaviour stays very regular for almost a week, with the aerosol-rich layer extending from the ground up to $3-3.5 \mathrm{~km}$. As further discussed in the next paragraphs, we anticipate here that the main factor driving this cycle is likely an enhanced hygroscopic growth of aerosol advected from the Po Valley from the afternoon to the early morning, with this effect also leading to the formation of low clouds within the aerosol layer at night (screened out as white areas in the figure). In fact, the transition from aerosol to the cloud phase is very sharp, as also noticeable from the sudden increase of more than $40 \mathrm{~W} \mathrm{~m}^{-2}$ in the downward infrared irradiance monitored at the same site (Fig. S2c).

Simultaneous ALC measurements in the city of Milan (see relative position in Fig. 2), which can be considered representative of the overall dynamics occurring within the Po basin, are shown in Fig. 4. An interesting feature here is that the modulation of the scattering ratio looks almost reversed compared to the Aosta-Saint-Christophe site, with a maximum SR at the surface at midday and minimum values during the night and the morning. While in the uppermost levels (> $3000 \mathrm{~m}$ a.s.l.) the synoptic circulation is blowing undisturbed from the west, the wind velocity at $500 \mathrm{~m}$ a.s.1. keeps alternating, likely driven by the breeze regime (the surface wind is affected by urban effects and does not show appreciable variations).

\subsubsection{Meteorological variables and back trajectories}

The observed reversal behaviour in Milan and Aosta already suggests that air mass movements are driving the clean-up of the lowermost levels in the Po plain and the transport of the aerosol plumes elsewhere. To substantiate this hypothesis, a careful analysis of the meteorological fields (observed and modelled) was performed. In particular, we verified that this selected sequence of days presents a typical pattern of plain-to-mountain wind systems during the afternoon of each day in Aosta-Saint-Christophe. Surface-level eastern wind speeds as high as $8 \mathrm{~ms}^{-1}$ are measured daily in the afternoon till sunset and are shown as bold arrows in the lowermost levels of Fig. 3a. Conversely, calm wind is detected during the night, i.e. when the aerosol layer thickens. Since no instrument is available at the measuring site to determine the vertical profile of the wind velocity, the simulations from the COSMO model are used to assess the wind field at several altitudes (thin arrows in Fig. 3a). It reproduces the thermal wind circulation in the lowest atmospheric layers well during the afternoon and slightly overestimates the mountain-to-plain drainage winds at night and early morning (this issue is discussed in Sect. 4.4). The thermally driven wind pattern forecasted by COSMO extends up to an altitude of $3000 \mathrm{~m}$, i.e. approximately the maximum height of the aerosol layer observed by the ALC (reasons for possible discrepancies of this simulated and measured altitude are discussed in Sect. 4.4). Note that wind direction is incompatible with Aosta being the potential source of the observed aerosol layer, as the city is located west of the observatory. At higher elevations, the wind field is clearly decoupled from that in the PBL and follows the large-scale circulation.

Complementary information is provided by the analysis of the $48 \mathrm{~h}$ back trajectories calculated by LAGRANTO using COSMO fields (Sect. 3.2.3) ending over the Aosta Valley in the period addressed (Figs. 5 and S3). For ease of clarity, the LAGRANTO output is shown in separate panels depending on the arrival altitude of each trajectory $(<2000$ and $>2500 \mathrm{~m}$ a.s.1.). These results show that before the episode (25 August and morning of 26 August, Fig. S3a and d) trajectories are driven by large-scale flows from the west and are thus parallel at all altitudes. Therefore, air masses reached Aosta after crossing the Alps, notably the Mont Blanc chain, hence transporting clear and unpolluted air from the free troposphere to the PBL. Then, in the afternoon of 26 August, back trajectories in the PBL change their provenance owing to the development of the thermal circulation tapping into air masses of very different origin (Fig. 5a), while higheraltitude trajectories mostly continue to follow the synoptic circulation (Fig. 5b). The lowermost trajectories cover a notable distance and cross some major conurbations of the Po basin, i.e. Milan and Turin, at altitudes lower than a few hundred metres above sea level, and thus well within the polluted PBL. This sudden reversal of the trajectories occurs simultaneously with the appearance of the elevated aerosol layers in the Aosta ALC image (Fig. 3a). These meteorological conditions persist for the rest of the day and in the following days. The analysis of the corresponding back trajectories confirms that transport of polluted air masses from the Po basin also occurs in the afternoons of the other days of this episode, until the flux changes again to a northwestern configuration (Fig. S3c and f).

To complete the picture, it is worth mentioning that the COSMO model also predicts an increase in the RH (Fig. 3b) from evening to early morning, almost simultaneous with the SR enhancement observed by the ALC. In this time frame, RH exceeds typical summertime deliquescence values reported for the Po basin in previous studies (e.g. DRH $=67 \%$, 




Figure 4. Vertical profile of scattering ratio from the ALC in Milan. Arrows: horizontal velocity of the wind measured at the surface (bold, lower arrows) and simulated by COSMO at several elevations (thin arrows).

(a)
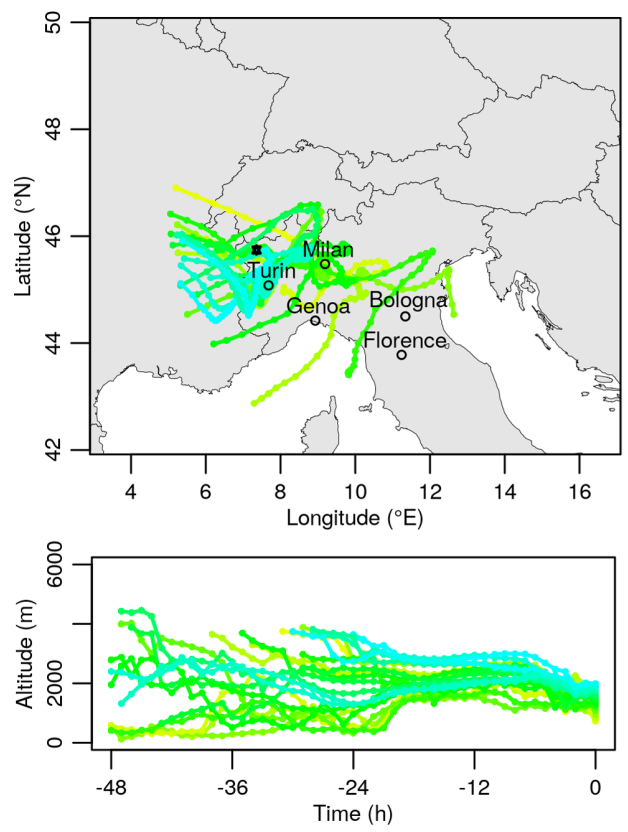

(b)

2015/08/26 18:00 UTC
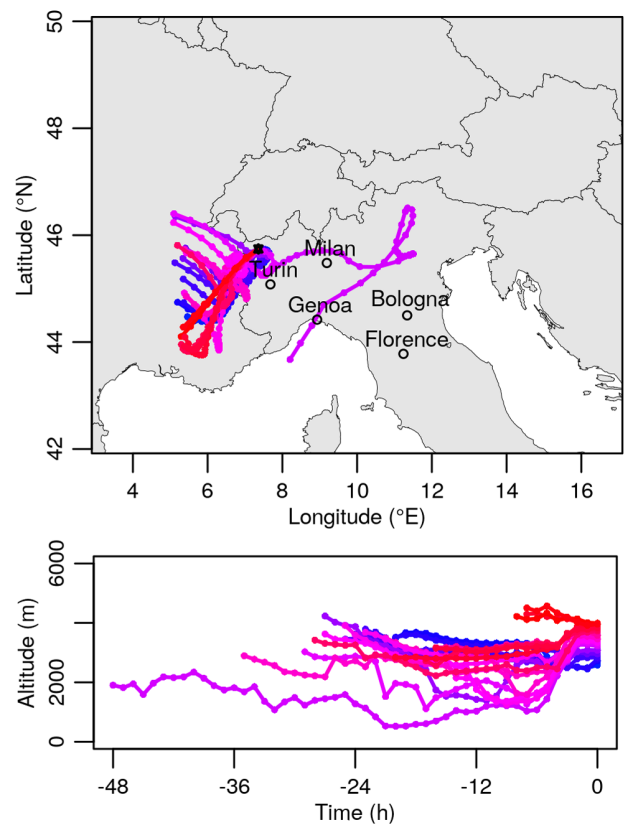

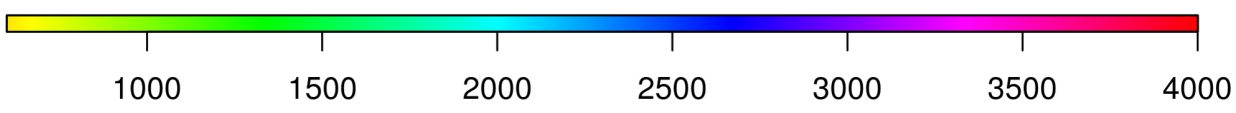

Trajectory arrival height ( $\mathrm{m}$ a.s.l.)

Figure 5. The $48 \mathrm{~h}$ back trajectories ending at Aosta-Saint-Christophe on 26 August 2015 at 18:00 UTC at altitudes lower than $2000 \mathrm{~m}$ a.s.l. (a) and higher than $2500 \mathrm{~m}$ a.s.1. (b). The trajectories are cut at the border of the COSMO model. The colour scale represents the back-trajectory arrival height. Corresponding altitudes of the back trajectories vs. time are reported in the bottom panels. The dots along each trajectory mark a $1 \mathrm{~h}$ step and the black star indicates the trajectory arrival point (Aosta-Saint-Christophe). A more complete sequence for the episode is shown in Fig. S3.

D'Angelo et al., 2016) and reaches up to $98 \%$ at the ground (Fig. S2b). This suggests hygroscopic growth on aerosols and a consequent increase in the ALC $\beta_{\mathrm{p}}$. For example, at a measurement site representative of Po Valley conditions, Adam et al. (2012) found a median increase in the aerosol backscat- ter coefficient of $70 \%$ for $\mathrm{RH}=90 \%$ compared to the dry case. During the day, RH decreases below typical crystallisation values in summer (e.g. CRH $=62 \%$, D' Angelo et al., 2016). As RH is clearly modulated by the temperature daily cycle, the measured specific humidity ( $\mathrm{SH}$ ) is also plotted 
on the same figure (Fig. S2b) as an additional variable independent of temperature, to identify potential advection of different air masses to the observation site. Indeed, a $\mathrm{SH}$ increase occurs on 26 August (starting from minimum values of $\sim 8 \mathrm{~g} \mathrm{~kg}^{-1}$ in the morning to about $11 \mathrm{~g} \mathrm{~kg}^{-1}$ in the evening) as soon as the wind starts blowing and high values $\left(>13 \mathrm{~g} \mathrm{~kg}^{-1}\right)$ endure for the rest of the week. This likely indicates that the dry air, typical of the more mixed mountain PBL (Henne et al., 2005; Mélin and Zibordi, 2005), is replaced by more stagnating, and humidified, air masses characteristic of hot summer days in the Po Valley (Bucci et al., 2018). This scenario is compatible with recent findings by Campanelli et al. (2018), who performed water vapour measurements with the POM-02 at Aosta-Saint-Christophe and found that moist air masses mainly come from the east. A discussion about the constancy of the measured SH during each day compared to the more variable values forecasted by COSMO is provided in Sect. 4.4. We anticipate here that this behaviour confirms that COSMO overestimates the nighttime drainage winds (characterised by lower $\mathrm{SH}$ ) and contributes to the observed discrepancies between the PM concentrations from FARM and the ALC.

\subsubsection{Mass concentrations}

We also show in Fig. 3c the altitude-resolved aerosol mass derived from the ALC backscatter coefficient (as described in Sect. 3.1.1). The maximum concentration within the aerosol layer is $>80 \mu \mathrm{g} \mathrm{m}^{-3}$. The corresponding $\mathrm{PM}_{10 \mathrm{w}}$ profile from FARM, partitioned between the non-local (coloured background) and local (contour line) pollution, is shown in Fig. 3d. FARM qualitatively reproduces the recurrent increase in the aerosol concentration at the end of each day and mainly ascribes it to particles transported by the thermal winds from the model-box boundaries. As an example, Fig. 6 provides a 3-D snapshot of the model simulation results, clearly showing the entrance of the aerosol-rich air mass from the Po basin to the Aosta Valley. The picture refers to 28 August 2015 at 15:00 UTC - the whole sequence of 26-31 August 2015 is available as a video file in the Supplement (https://doi.org/10.5446/38391). Still, there are two important differences between the FARM model simulations and the ALC observations in terms of (1) absolute $\mathrm{PM}_{10 \mathrm{w}}$ concentrations and (2) timing of the phenomenon. In fact,

1. $\mathrm{PM}_{10 \mathrm{w}}$ values from FARM are much lower than the ones retrieved from the ALC (about $-40 \%$ outside the thick aerosol layer identified by the ALC at night and even $-80 \%$ inside the layer);

2. the maximum $\mathrm{PM}_{10 \mathrm{w}}$ simulated concentration during the advection is anticipated by several hours (up to 6$7 \mathrm{~h}$, in the worst cases) compared to the ALC measurements, which, in contrast, show a better correlation with the $\mathrm{RH}$ profile by COSMO.
Possible reasons, such as hygroscopicity effects and modelling deficiencies, explaining the above-mentioned issues are further discussed in Sect. 4.4.

To evaluate the impacts on surface air quality parameters during the episode, hourly $\mathrm{PM}_{10}$ concentrations at the surface as measured in Aosta-downtown and simulated by FARM in Aosta-Saint-Christophe are presented in Fig. 3e ( $\mathrm{PM}_{10}$ monitoring at La Thuile was not yet operational at that time). Apart from two spikes $\left(80 \mu \mathrm{g} \mathrm{m}^{-3}\right)$ on 25 and 26 August (presumably of local origin), the concentrations measured in Aosta-downtown by the TEOM show a slight increase after the arrival of the layer, but without sudden jumps. Also, PM concentrations are generally higher during daytime compared to the night, according to the expected cycle of the summertime local sources (e.g. traffic, resuspension). These features, however, can be connected to the fact that mass loss occurs in TEOM due to secondary aerosol volatility, as better discussed in the companion paper by comparing the daily $\mathrm{PM}_{10}$ cycle from this instrument and the Fidas OPC in Aosta-Saint-Christophe. Moreover, this volatility could be different between nighttime and daytime, which would also contribute to the observed daily behaviour. In addition, FARM estimates at the surface are again lower than measurements ( $-60 \%$, on average). Daily $\mathrm{PM}_{10}$ concentrations observed with Opsis SM200 instruments during the case study in Aosta-downtown and Donnas are shown in Fig. 7, which includes the whole episode (correlation index with TEOM measurements $\rho=0.84$ ). The shaded area corresponds to those dates affected by the thick layers as revealed by the ALC. An increase in daily concentrations (up to maximum values of $10 \mu \mathrm{g} \mathrm{m}^{-3}$ for $\mathrm{PM}_{2.5}$ and $16-22 \mu \mathrm{g} \mathrm{m}^{-3}$ for $\mathrm{PM}_{10}$ ) can be clearly noticed at both sites, leading to concentrations slightly higher than average for the same period $\left(7 \mu \mathrm{g} \mathrm{m}^{-3}\right.$ for $\mathrm{PM}_{2.5}$ in Aosta-downtown and $12 \mu \mathrm{g} \mathrm{m}^{-3}$ for $\mathrm{PM}_{10}$ at both sites, considering the 2015-2017 series). The statistical significance of such PM increases during these transport episodes, compared to the natural variability in the aerosol load in non-advection conditions, is assessed in the companion paper using the full dataset. The daily averages of the simulated aerosol concentrations at the surface are superimposed on the same figure (dashed lines). While the model qualitatively reproduces the average load of $\mathrm{PM}_{2.5}$ and its variations in Aosta-downtown, it underestimates $\mathrm{PM}_{10}$ at both stations as already noticed.

\subsubsection{Sun photometer measurements}

Since sun photometric measurements only can be performed in daylight, results are often unavailable at those times when the ALC shows the greatest backscatter signal, i.e. in the evening and at night. However, data collected by the POM-02 radiometer can still be effective to monitor the first (late afternoon) and last (early morning) dynamics of the aerosol layer as seen by the ALC (Fig. 3a), and particularly tell us if this signal is detectable in the sun-photometer-derived, column- 


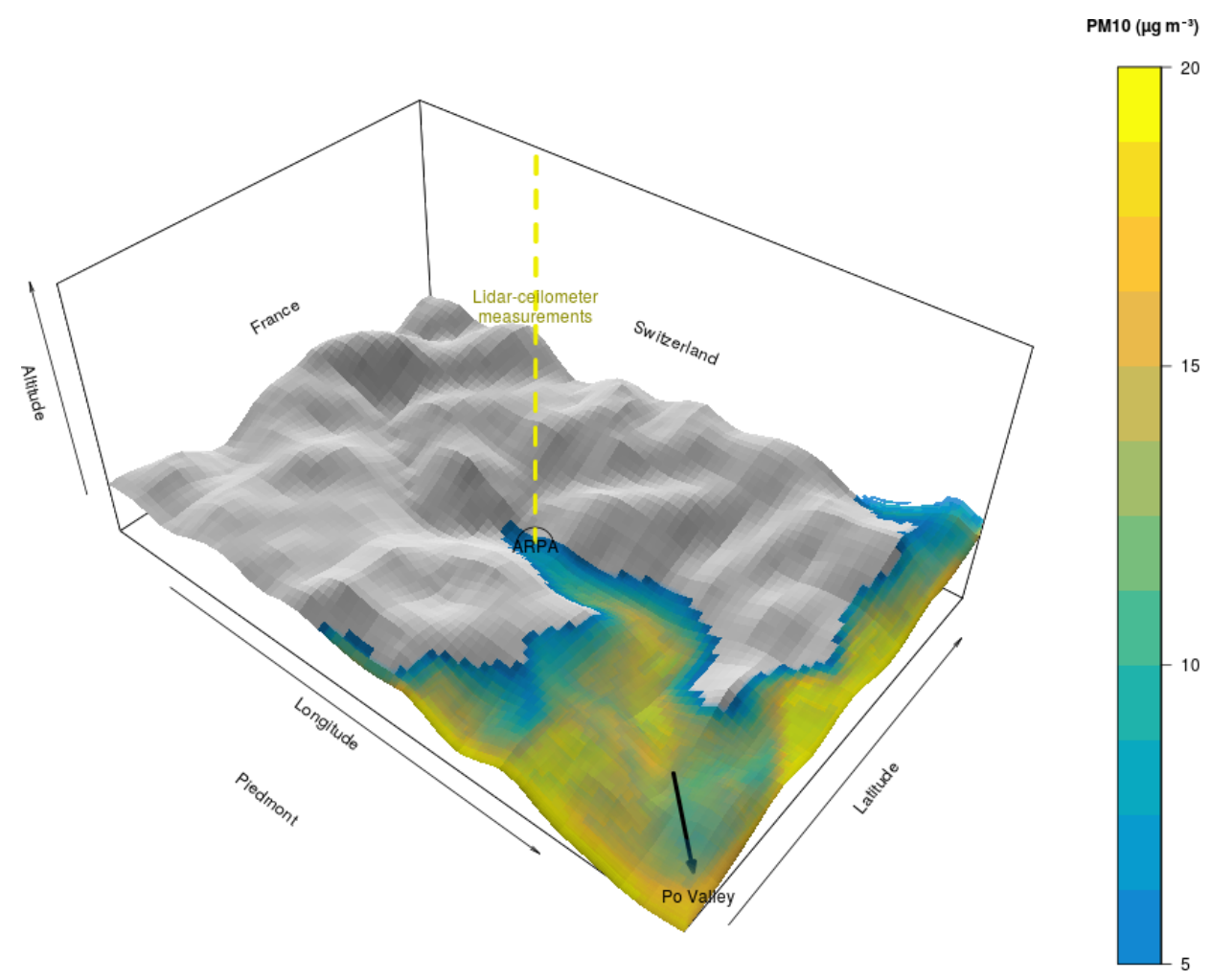

Figure 6. Still frame of the three-dimensional simulation of $\mathrm{PM}_{10}$ concentration by FARM (image from 28 August 2015 at 15:00 UTC). The image clearly shows the entrance of the aerosol-rich air mass from the Po basin into the Aosta Valley (yellow-blue area). The same colour scale as in Figs. 3d, 9d, and 12d is used (the lowest concentrations are removed for ease of representation). The sequence on 2631 August 2015 is available as a video file in the Supplement (https://doi.org/10.5446/38391).

integrated aerosol load. AOD obtained from the sun photometer (Fig. S2d) varies from 0.02 (25 and 26 August before appearance of the layer) to 0.07 (29 August, morning) at $1064 \mathrm{~nm}$ (approximately 0.05 to 0.2 at $500 \mathrm{~nm}$ ) and closely follows the AOD obtained by vertically integrating the extinction coefficient from the ALC over the atmospheric column. The two independent AOD retrievals present a mean bias of -0.007 and standard deviation of the differences of 0.006, both lower than the declared uncertainty of the POM sun photometer itself (about 0.01) (Campanelli et al., 2007). The good closure with the AOD from the photometer demonstrates the reliability of the functional relationships derived by Dionisi et al. (2018) and employed in our ALC inversion algorithm, at least during the daytime.

Further retrieval products from SUNRAD.pack and SKYRAD.pack (displayed in Fig. S2e) show the Ångström exponent to increase from 1.2 to 1.7 on 26 August from 08:00 to 17:00 UTC, suggesting the advection of smaller particles in the atmosphere, and to remain almost constant (about 1.6, a typical value for the Po Valley, as already described by Mélin and Zibordi, 2005, and Kambezidis and Kaskaoutis, 2008) in the following days. These values should be compared to the lower Ångström exponents typically measured in the Aosta Valley, i.e. $\sim 1.1$ on average (Diémoz et al., 2014a, 2019). Likewise, the single-scattering albedo (SSA) at $500 \mathrm{~nm}$ increases (from 0.7 to 0.95 ) on 26 August, which is compatible with the arrival of more scattering (likely secondary aerosol, as described in Sect. 4.2.4 and 4.3.4) and/or more aged aerosol, such as that from the Po Valley (Barnaba et al., 2007; Gilardoni et al., 2014). The sun-photometerderived total-column aerosol volume distribution (Fig. S2f) peaks in the accumulation mode (about $0.3 \mu \mathrm{m}$ ). A slight decrease in the peak diameter in the morning (from about 0.4 to $0.2 \mu \mathrm{m}$ ) can be noticed on some days (e.g. 27-30 August) and might be ascribed to the dehydration of the particles as temperature increases and RH decreases. The same behaviour can be observed better in the third case study (Sect. 4.3.5 and Fig. S9g).

\subsubsection{Spatial extent of the observed phenomenon}

In order to provide a first evaluation of whether the phenomenon observed and described in detail for the Aosta area could have a more general validity in the Alpine region, we used AOD data retrieved from space over northern Italy. In particular, we exploited the high-resolution capabilities of the MODIS-MAIAC AOD product (Sect. 3.1.3) and the availability of two MODIS overpasses during the day (Terra 



Figure 7. Measured (coloured bars) and simulated (dotted line) daily averages of $\mathrm{PM}_{2.5}$ and $\mathrm{PM}_{10}$ concentrations at Aostadowntown and Donnas during case study 1 (August 2015). The period when the ALC detects a thick layer above Aosta-SaintChristophe is highlighted with a grey background. $\mathrm{PM}_{2.5}$ measurements in Aosta are missing for 2 September 2015.

and Aqua platforms), to detect signs of the described effects at the regional scale. Figure 8a shows the average difference between the AOD retrieved each day from MODIS Aqua (overpass time between 12:00 and 13:00 UTC) and that from MODIS Terra (10:00-11:0 UTC). Despite the short time lag between the Terra (AM) and Aqua (PM) satellite overpasses, this figure shows that the data are sufficient to start detecting an overall reduction of the AOD in the Po basin (blue area) and a reverse increase in the mountain areas (Alps and Apennines) surrounding it. The general picture suggests a sort of aerosol drainage from the Po Valley (negative AOD difference, blue) to the Alps (positive AOD difference, red), although some aerosol dehydration from the morning to the afternoon could also partially contribute to the observed morning and afternoon differences. This provides an observationbased confirmation of the hypothesis of aerosol transport, in agreement with our previous results from FARM (e.g. Fig. 6 and the relative video file), and with wind simulations from COSMO over the same area (averaged over the same hours between Terra and Aqua overpasses, Fig. 8b). Valleymountain (and sea-land) breezes are clearly reproduced, as expected on days with weak synoptic flows and strong heating by the sun.

\subsection{Case study 2: winter (January 2017)}

A second pollution transport episode was chosen for its significance and its consequences on air quality. Indeed, the last days of January 2017 and the first ones of February 2017 were characterised by heavy exceedances of $\mathrm{PM}_{10}$ in the whole Po basin with concentrations of nearly $300 \mu \mathrm{g} \mathrm{m}^{-3}$ in some stations of northern Italy (Bacco et al., 2017). This situation was driven by conditions of strong atmospheric stability, weak winds, low mixing height, and presence of clouds and additionally worsened by the transit of a warmer air mass aloft, i.e. the typical circumstances causing the most severe air pollution episodes in the Po basin in winter (Finardi and Pellegrini, 2004). Chemical analyses accomplished in the framework of the air quality monitoring network in northern Italy identified considerable formation of secondary particulate (e.g. ammonium nitrate), also confirmed by very large $\mathrm{PM}_{2.5} / \mathrm{PM}_{10}$ ratios (almost 0.9).

In the Aosta Valley, this pollution episode lasted only from 26 to 29 January. At that time, the Alps were contended by a pressure trough at the north and a ridge at the south. At the beginning of the period, the influence of the low-pressure system prevailed and brought cloudy skies over the valley. Although local emissions (e.g. residential heating and traffic, additionally worsened by the temperature inversion) might have also increased in this period, the influence of pollution transport from the Po basin is unambiguous. As a result of the advection, the PM concentrations measured in the Aosta Valley were found to be significant in the whole region (e.g. $\mathrm{PM}_{10}>100 \mu \mathrm{g} \mathrm{m}^{-3}$ in Aosta-downtown and Donnas), even at some remote measuring sites (e.g. $\mathrm{PM}_{10} \sim 70 \mu \mathrm{g} \mathrm{m}^{-3}$ in Antey, Sect. 4.2.3), and remarkably higher than the average concentrations in the same period (e.g. $33 \mu \mathrm{g} \mathrm{m}^{-3}$ for $\mathrm{PM}_{10}$ and $23 \mu \mathrm{g} \mathrm{m}^{-3}$ for $\mathrm{PM}_{2.5}$ in Aosta-downtown in 2015-2017). No sun photometric measurements were available for this period due to clouds and major maintenance to the POM-02 instrument.

\subsubsection{ALC observations}

The profiles from the ALC in Aosta-Saint-Christophe for this winter case are depicted in Fig. 9a and show the sudden appearance of a thick aerosol layer in the afternoon of 26 January. Unlike the previous case, the ALC measurements do not reveal distinct features for each day of the sequence, but rather a continuous and persisting layer during the whole episode. The SR reaches values above 30 in the night between 26 and 27 at altitude, and, closer to the surface, between the evening of 27 and the morning of 29 January. The layer extends up to $2000 \mathrm{~m}$ a.s.l., a clear signature of the nonlocal origin of the air mass. Some clouds are visible above and within the aerosol layer. The episode ends on 29 January as quickly as it began, with clearer air taking the place of the polluted air mass starting from above and subsequently eroding the layer down to the surface.

Simultaneous ALC profiles over Milan are depicted in Fig. 10. As opposed to the Aosta Valley, the aerosol layer does not vanish on 29 January, but remains for a few days longer, although the winds at altitude change their prove- 


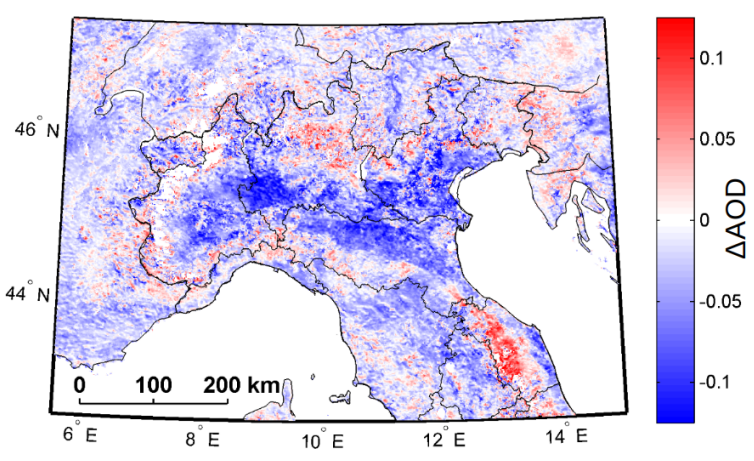

(a)



(b)

Figure 8. (a) Average difference between AOD estimated from Aqua and Terra satellites during 27-31 August 2015 using the MAIAC algorithm. (b) Horizontal wind velocity from COSMO (arrows); vertical velocity (red and blue contours, $\pm 0.1 \mathrm{~ms}^{-1}$ ) over the same domain and the same hours as in (a).

nance from the west on that day. Clouds only form from 27 January, presumably allowing solar radiation to trigger a weak breeze tide in the lowest $2000 \mathrm{~m}$ on that day, whilst strong stability favours calm wind in the following days.

\subsubsection{Meteorological variables and back trajectories}

The wind field over Aosta-Saint-Christophe, depicted in Fig. 9a, presents a very different pattern compared to the first case addressed (Fig. 3a). Firstly, calm wind is measured for the whole period at the bottom of the valley. This is due to a shallow temperature inversion in the lower atmospheric layers in the main valley. Conversely, at the SaintDenis station, located above the inversion layer, and at the Donnas station, where the temperature inversion is weaker, the wind pattern is more representative of the wider circulation: for example, the average wind speed in Saint-Denis is about $4 \mathrm{~m} \mathrm{~s}^{-1}$ on 26 January in the afternoon (Fig. S4e) and the wind clearly turns from west (morning) to east (afternoon), simultaneously with the appearance of the layer. The same wind change is detected in Donnas on the same day (Fig. S4f), with easterly wind speeds $>1 \mathrm{~m} \mathrm{~s}^{-1}$ for several hours in the afternoon. As a further difference with the first case, the forecasted wind at 1000-2000 $\mathrm{m}$ a.s.l. does not show any change in direction typical of the thermal winds. For example, at $2000 \mathrm{~m}$ a.s.l. the circulation is continuous and vigorous (up to $6 \mathrm{~m} \mathrm{~s}^{-1}$ ), from the afternoon of 26 to the beginning of 29 January. Indeed, this winter case study interestingly shows that thermally driven winds are not the only mechanism, especially in winter, driving the advection of air masses from the Po Valley to the Alps. Rather, the synoptical circulation can push the air masses towards the Alpine valleys, as in this case. In fact, the flow clearly reveals its southern origin at elevations above the mountain crest (e.g. $3000 \mathrm{~m}$ a.s.1.), where the wind is not channelled within the main valley. At that altitude, the wind speed is even greater than $20 \mathrm{~m} \mathrm{~s}^{-1}$. Finally, on 29 January, the measurements in Saint-Denis (gradual increase in the speed of westerly wind) and in Donnas (even stronger wind, again from the west), and COSMO simulations (wind reversal at 1000-2000 m a.s.l.) correlate with the disappearance of the layer better than observations performed at the bottom of the valley (calm wind).

Back trajectories for 26 January are plotted in Fig. S6 and indicate transit over the Po basin starting from the morning (panels a, d), which seems to contradict the fact that the layer arrival over the Aosta Valley is detected by the ALC only since the afternoon. This can be explained by noting that the mean altitude of the trajectories crossing the Po basin during the morning exceeds $1500 \mathrm{~m}$ a.s.l. and is thus higher than the Po Valley aerosol layer observed by the ALC in Milan (Fig. 10). The trajectory altitude tends to decrease in the afternoon, reaching the elevations of the polluted boundary layer (Fig. S6b) and thus leading to effective aerosol transport to the Aosta Valley. In fact, considering that each dot in Fig. S6b represents a $1 \mathrm{~h}$ step, we estimate a mean air mass residence time in the Po Valley PBL of 30-35 h before arriving over the observing site. Finally, trajectories turn westerly on 29 January, in agreement with the removal of the layer over Aosta (Fig. S6c and f).

Together with the appearance of the aerosol layer, an increase in the COSMO RH can be noticed (Fig. 9b). The latter remains higher, above typical wintertime deliquescence values (e.g. $\mathrm{DRH}=54 \%$, D'Angelo et al., 2016), for the whole duration of the episode, and never drops below the crystallisation point (e.g. $\mathrm{CRH}=47 \%$ ), which can also be partly attributed to the presence of low clouds forecasted by the NWP model, as actually occurred. The advection is detected more clearly by the increase in $\mathrm{SH}$ measured at ground level (from less than $2 \mathrm{~g} \mathrm{~km}^{-1}$ to a maximum of $4 \mathrm{~g} \mathrm{~kg}^{-1}$ on 28 January, Fig. S4b). For this episode, the arrival of a different air mass is additionally revealed by the tempera- 

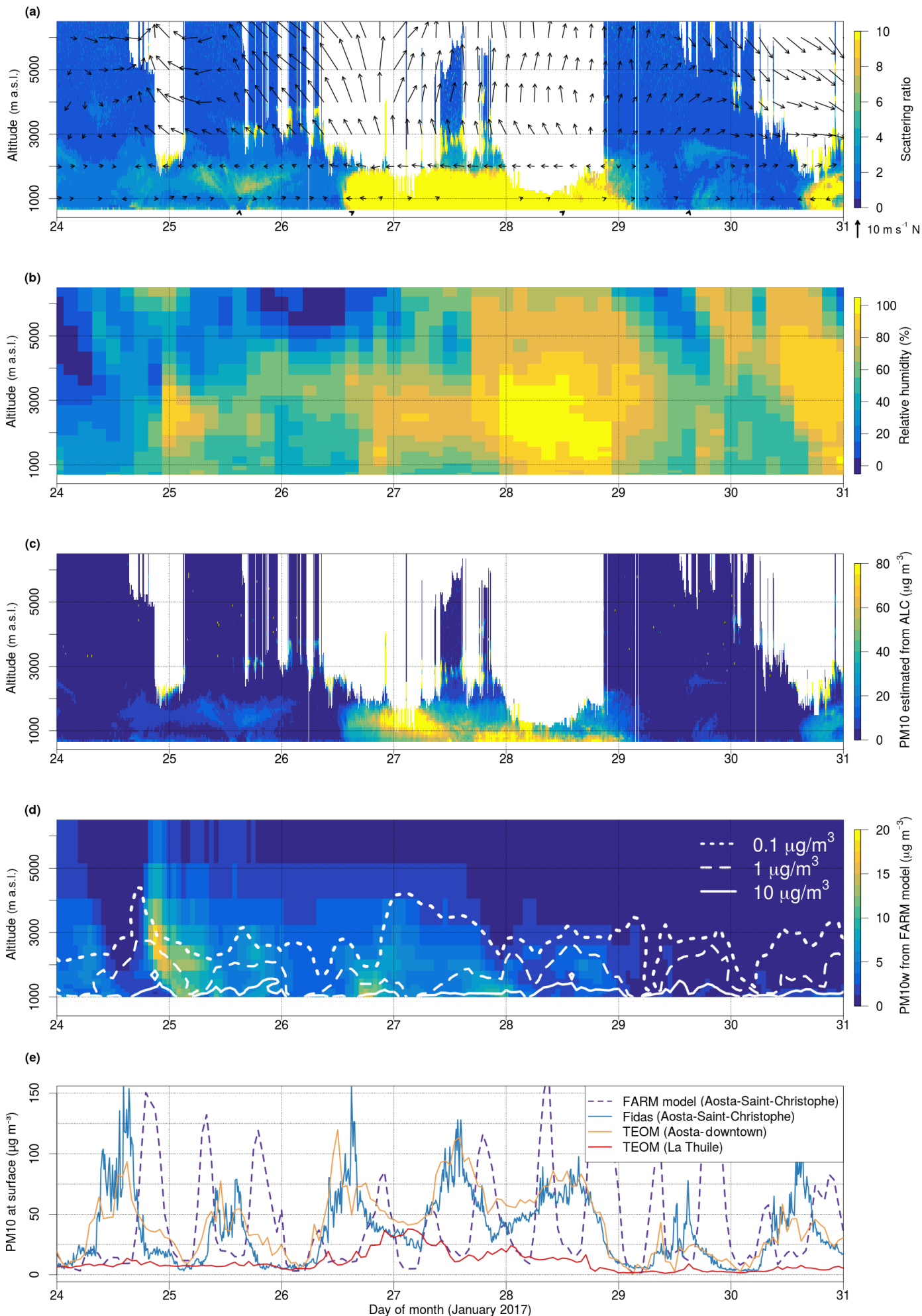

Figure 9. Case study of 24-30 January 2017. (a) Coloured background: vertical profile of scattering ratio from ALC in Aosta-SaintChristophe. Arrows: horizontal velocity of the wind measured at the surface and simulated by COSMO at several elevations. (b) Vertical profile of relative humidity forecasted by COSMO. (c) Vertical profile of $\mathrm{PM}_{10}$ mass concentration derived from the ALC using the functional relationships. (d) Mass concentration $\left(\mathrm{PM}_{10 \mathrm{w}}\right.$ ) from FARM. (e) Hourly and sub-hourly PM $_{10}$ (dry) surface concentration from FARM simulations and observations in Aosta-Saint-Christophe, Aosta-downtown, and La Thuile (the $y$ scale of this panel is extended compared to Figs. 3 and 12). 




Figure 10. Vertical profile of scattering ratio from the ALC in Milan (24-30 January 2017). Arrows: horizontal velocity of the wind measured at the surface (bold, lower arrows) and simulated by COSMO at several elevations (thin arrows).

ture and humidity sensors along the mountain slope. Pseudoequivalent potential temperatures at different altitudes are shown in Fig. S5. As clearly noticeable, the spread among the series recorded at $550 \mathrm{~m}$ a.s.l. and that at higher altitudes remarkably, and quickly, decreases on 26 January, especially during the night, suggesting that the strong (and very shallow) temperature inversion weakens and mixing of the upper aerosol layers down to the surface is favoured.

\subsubsection{Mass concentrations and particle measurements at the surface}

The mass concentration retrieved within the layer by the ALC (Fig. 9c) is quite variable (from $30 \mu \mathrm{g} \mathrm{m}^{-3}$ at the edge of the layer to more than $100 \mu \mathrm{g} \mathrm{m}^{-3}$ at the core) and reveals the heterogeneous distribution of the particulate inside the layer. FARM predicts a very different scenario, with three separate increases at the end of 26,27 , and 28 January of nonlocal origin (coloured background in Fig. 9d, much lower than the concentration retrieved by the ALC) and a clear diurnal cycle close to the surface of local origin (Fig. 9e). The diurnal cycle in the simulations is characterised by two peaks corresponding to the combined effect of traffic rush hours, residential heating, and variation in the mixing layer height. Hourly and sub-hourly $\mathrm{PM}_{10}$ surface concentration measurements at both Aosta-downtown and Aosta-SaintChristophe, however, only exhibit one peak at midday. Taking into consideration these different daily evolution patterns and the sources included in the emission inventory, the most likely reasons for the differences between the model and the measurements at the surface appear to be an underestimation of the residential heating (actually switched on all day during these very cold days) and an overestimation of the traffic road contribution, together with an overestimation of the mixing layer height growth at midday by the NWP model. Anyway, Fig. 11 shows that the daily averages of PM concentrations measured at several sites of the region are higher on 27-28 January than on the neighbouring days. Specifi- cally, the increase is similar (more than $40 \mu \mathrm{g} \mathrm{m}^{-3}$ ) for both $\mathrm{PM}_{2.5}$ and $\mathrm{PM}_{10}$ in Aosta-downtown, which results from the fact that the increment is mainly driven by particles with a diameter of less than $2.5 \mu \mathrm{m}$. The maximum $\mathrm{PM}_{10}$ concentration $\left(117 \mu \mathrm{g} \mathrm{m}^{-3}\right)$ was measured on 28 January in Donnas (Fig. 11h), which is the closest station to the Po basin. The spatial pattern of the observed increase, not fully captured by the model, is evident in Fig. S7 and represents a further indication of the Po Valley being the source of the polluted air masses. Moreover, Fig. 11c, d show this increase to be associated with enhancement in Aosta-downtown of the nitrate and ammonium components (see next paragraph), two key species of the Po Valley secondary aerosol, but minor contributors to $\mathrm{PM}_{10}$ in the Aosta Valley. Finally, while the daily PM concentrations from FARM are comparable, on average, to the measurements, the modulation of the PM concentration by the advection (peaks) is not captured by the model, whose output is rather constant. Most interestingly, data collected at remote and usually pristine sites also show a remarkable increase: at $\mathrm{La}$ Thuile $\left(\mathrm{PM}_{10}\right.$ winter average $7 \mu \mathrm{g} \mathrm{m}^{-3}$ ), the hourly $\mathrm{PM}_{10}$ concentration (Fig. 9e) reaches nearly $40 \mathrm{\mu g} \mathrm{m}^{-3}$ (some hours later than the appearance of the aerosol layer in Aosta-Saint-Christophe) and correlates well with the increasing $\mathrm{NO}_{2}$ concentration (from about $2 \mu \mathrm{g} \mathrm{m}^{-3}$ before and after the event to $44 \mu \mathrm{g} \mathrm{m}^{-3}$ during the event on an hourly basis) measured by a co-located detector. Additionally, the mobile laboratory in Antey (winter average $20 \mu \mathrm{g} \mathrm{m}^{-3}$ ) measures increasing daily $\mathrm{PM}_{10}$ concentrations with a maximum of $69 \mu \mathrm{g} \mathrm{m}^{-3}$ on 27 January (Fig. 11g) and increasing $\mathrm{NO}_{2}$ concentrations from about 30 to $56 \mu \mathrm{g} \mathrm{m}^{-3}$.

For this selected sequence of days, the data collected by the OPC in Aosta-Saint-Christophe are additionally available. The instrument reveals a notable increase in the number concentration for particles smaller than $0.5 \mu \mathrm{m}$ (Fig. S4c) in coincidence with the arrival of the aerosol layer. The total number concentration (Fig. S4d) gradually increases from a few hundred up to 3000 particles $\mathrm{cm}^{-3}$ and decreases again 



Figure 11. Measured (coloured bars) and simulated (dotted line) $\mathrm{PM}_{2.5}$ and $\mathrm{PM}_{10}$ daily concentrations at several sites of the Aosta Valley (a, b, $\mathbf{g}, \mathbf{h})$; percentage concentrations of nitrate (c), ammonium (d), and sulfate (e) and OC/EC ratio (f) at Aosta-downtown during case study 2 (January 2017). The period when the ALC detects a thick layer above Aosta-Saint-Christophe is highlighted with a grey background.

on 29 January (the average value in winter 2016-2017 in conditions of local pollution being 650 particles $\mathrm{cm}^{-3}$ ).

\subsubsection{Chemical analyses}

Some results of anion-cation analyses performed on daily samples collected at Aosta-downtown are also reported in Fig. 11 and presented in terms of relative concentrations (ratio between ion mass and $\mathrm{PM}_{10}$ ). As anticipated, the fractions of nitrate and ammonium drastically increase during the event, reaching values more than double (nitrate) or even 8 to 10 times as much (ammonium) compared to the concentrations in the days adjacent to the case study. Indeed, wintertime low temperature and high humidity in the Po Valley represent the best conditions leading to the formation of ammonium nitrate (Schaap et al., 2004). In addition, this nitrate increase enhances the observation of a lowering of DRH (D'Angelo et al., 2016) that may influence the ALC backscatter. Sulfate also increases, but not as much as nitrate and ammonium since unfavourable conditions are met during winter (Carbone et al., 2010). Only one sample was analysed for $\mathrm{EC}$ and $\mathrm{OC}$ during the event, and the OC/EC ratio increases only marginally, likely due to sample overloading. In general, variations in the aerosol composition are noticeable on 27-28 January and in line with transport from the Po basin (as more rigorously demonstrated using the positive matrix factorisation method in the companion paper). Indeed, a high presence of secondary aerosol, most notably nitrate compounds, in the Po Valley has been documented for a long time (Schaap et al., 2004; Putaud et al., 2010; Saarikoski et al., 2012; Aksoyoglu et al., 2017). These are probably enhanced by the particular atmospheric conditions during the examined period (Bacco et al., 2017). All together, nitrate, ammonium, and sulfate can explain about $40 \%$ of the $\mathrm{PM}_{10}$ mass during the episode (as a reference, this fraction represents $15 \%$ of the $\mathrm{PM}_{10}$ mass for non-advection days of January-February 2017, on average, owing to missing sources of precursors in the Aosta Valley), while organic matter $(\mathrm{OM}$, assuming a typical conversion factor of 1.6 between the measured concentration of $\mathrm{OC}$ and the unknown concentration of OM; as in Turpin and Lim, 2001 and Curci et al., 2015 for urban sites) and EC account for the remaining $30 \%$ and $5 \%$ fractions, respectively (similar percentages are obtained for non-advection days in January-February 2017). Finally, the relative concentration of the other measured ions, allegedly of local origin (e.g. $\mathrm{Na}^{+}$and $\mathrm{Cl}^{-}$from road salting, not shown), does not follow the same pattern as observed in Fig. 11. Figure 11c-e also reveal that FARM is not able to reproduce the experimental chemical speciation: nitrate is strongly underestimated, while ammonium and sulfate are strongly overestimated, and the simulations of the OC/EC ratio do not follow the experimental data. This behaviour is probably to be ascribed to the fact that the SPECIATE v3.2 chemical characterisation implemented in the emission manager is not suitable for the considered sources and/or that the sources, and therefore their chemical profiles, are not accurately identified.

\subsection{Case study 3: spring (May 2017)}

This third case, occurring in spring, is similar to the first one (Sect. 4.1) but is included to represent a third season and because a more extended observational dataset was available. From a meteorological point of view, a wide high-pressure ridge extended from the Mediterranean Sea to western and central Europe, thus favouring sunny days with afternoon instabilities and thermally driven winds from the Po basin to the Aosta Valley. At the end of the period, a weakening of the high-pressure area led to increased instability. The whole advection episode (25 May-3 June 2017) lasted for 10 con- 
secutive days. In the next paragraphs, we will mainly focus on the interval of 24-30 May.

\subsubsection{ALC observations}

Since the establishment of the thermally driven wind regime, starting from 25 May, a thick aerosol layer is regularly detected by the ALC in the afternoon (Fig. 12a). The layer persists during each night, when the scattering ratio increases up to a value of 20 and clouds systematically form within the layer. This aerosol layer extends from the ground to an altitude increasing from $2.5 \mathrm{~km}$ at the beginning of the case study to more than $3 \mathrm{~km}$ at the end of the episode.

\subsubsection{Meteorological variables and back trajectories}

The plain-to-mountain circulation, driving the phenomenon under investigation, is well captured by both measurements at the surface (Fig. 12a, bold arrows) and COSMO forecasts (thin arrows). Eastern winds with speeds $>10 \mathrm{~m} \mathrm{~s}^{-1}$ are measured in the afternoon till sunset at the surface, while nights are characterised by calm wind. At higher elevations, the wind provenance turns from the north, at the start of the depicted sequence, to the south.

The back trajectories ending over the Aosta Valley during the third episode are plotted in Fig. S8. On 25 May, the largescale circulation from the north generally dominates the air mass origin (Fig. S8a and d). However, during the day, the low-level thermal circulation becomes strong enough to influence the lowest trajectories, which start to cross the Po Valley in the second part of the day (Fig. S8b), in line with the simultaneous appearance of an aerosol layer in the ALC measurements. Together with their rotation during this day, the trajectories also decrease their altitude. At the end of the day, the air masses reaching the station travelled for more than $20 \mathrm{~h}$ on the surface of the Po basin. The end of the episode is marked again by northwestern provenance (Fig. S8c and f).

As in the first case, COSMO accurately predicts the advection of humid air at the same times as the ALC detects a thickening of the layer (Fig. 12b). At night, the simulated and measured RHs exceed $90 \%$ at altitude and $80 \%$ at ground level (Figs. 12 and S9b). Contrary to RH, SH does not show any daily cycle (Fig. S9b). A sudden SH increase ( 5 to $10 \mathrm{~g} \mathrm{~kg}^{-1}$ ) is clearly visible on 25 May at the time of the advection, while the values for the following days are almost constant except on the occasion of short showers (e.g. evening of 28 May).

\subsubsection{Mass concentrations and particle measurements at the surface}

The aerosol mass derived from the ALC is presented in Fig. 12c. The maximum concentration retrieved by this method within the aerosol layer is higher than $60 \mu \mathrm{g} \mathrm{m}^{-3}$ just before the formation of clouds at night. Again, FARM (Fig. 12d) qualitatively reproduces the afternoon increase in aerosol concentrations owing to transport from the boundaries; however the simulated concentrations are much lower (about 4-5 times) than the retrievals from the ALC and the advection arrival times are anticipated compared to the appearance of the thick layer from the ceilometer.

Hourly and sub-hourly PM $_{10}$ surface concentrations (measured in Aosta-downtown and Aosta-Saint-Christophe and simulated by FARM) are presented in Fig. 12e. FARM correctly reproduces the morning rush-hour peak, but the concentrations are about half those from the PM samplers. The series in Fig. 12e shows an increase in $\mathrm{PM}_{10}$ surface concentration during 25 May, with persisting high values for the rest of the week, most noticeably during the night. Accordingly, PM daily means in Fig. 13a, b, g, h show a distinct increase in the whole region (the concentrations doubles) during the case study compared to the preceding and following days (and also compared to the 2015-2017 average concentrations for the same period, i.e. $12 \mu \mathrm{g} \mathrm{m}^{-3}$ for $\mathrm{PM}_{10}$ in Aosta-downtown and Donnas and $6 \mu \mathrm{g} \mathrm{m}^{-3}$ for $\mathrm{PM}_{2.5}$ in Aosta-downtown).

The number distribution and total particle number measured by the OPC in Aosta-Saint-Christophe are plotted in Fig. S9c and d, respectively. Figure S9 shows a notable increase in the number concentration during 25 May (from less than 200 to more than 800 particles $\mathrm{cm}^{-3}$ ) and in the afternoon of each day, and a decrease in the central part of each day as soon as the valley convection starts and the mixing layer height increases.

\subsubsection{Chemical analyses}

Percentage concentrations of nitrate, ammonium and sulfate are represented in Fig. 13c-e and account for about $20 \%-$ $25 \%$ of the total $\mathrm{PM}_{10}$ mass (as a reference, this fraction represents less than $15 \%$ for non-advection days in MayJune 2017). Interestingly, relative nitrate concentration does not change much and does not reach the extreme values of the winter case study. Indeed, transfer of ammonium nitrate from particles to the gas phase, which is not measured, is favoured by higher temperatures (Saarikoski et al., 2012). Conversely, ammonium and sulfate increase remarkably during advection, reaching typical concentrations of the Po Valley in that period (Putaud et al., 2010). In particular, the sulfate concentration is much higher and more affected by the advection in May than during the winter case. The role reversal between nitrate and sulfate in case studies 2 and 3 results from the different sensitivity of those compounds to temperature and atmospheric conditions (Carbone et al., 2014). Again, the contribution of inorganic species from the model does not agree with the analyses: the contribution by ammonium and sulfate is strongly underestimated, while the peaks in the simulated nitrate concentration are not reflected in the analyses.

As for the organic part, OM and EC are the main constituents of the remaining fraction, with about $60 \%$ and $6 \%$, respectively. Although the available dataset is rather short, the $\mathrm{OC} / \mathrm{EC}$ ratio during the event almost doubles (values of 

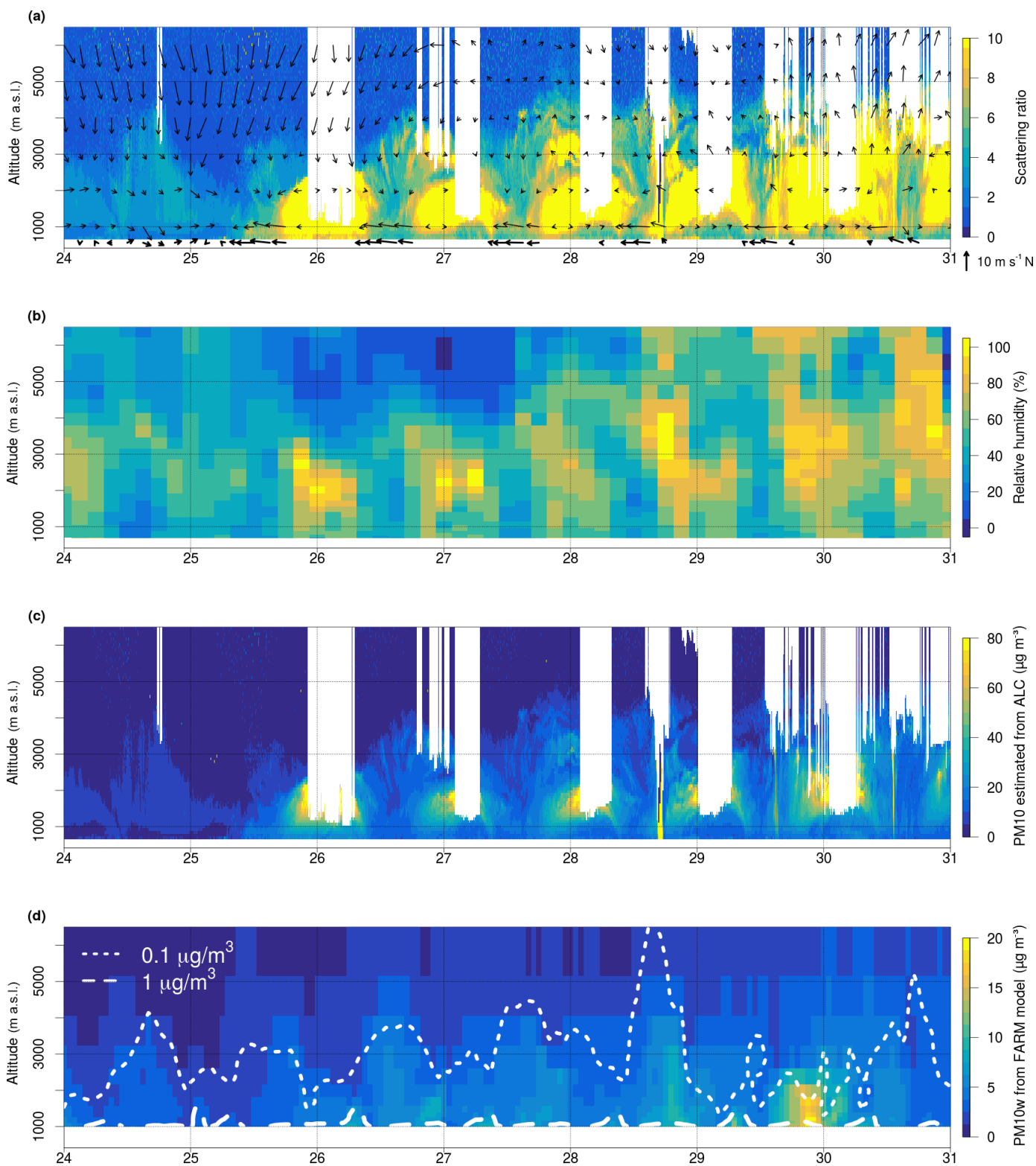

(e)

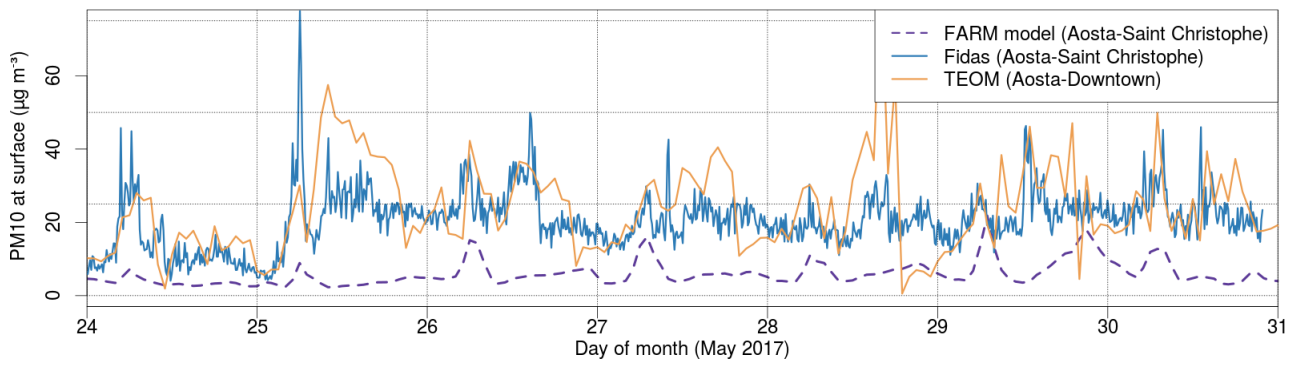

Figure 12. Case study of 24-30 May 2017. (a) Coloured background: vertical profile of scattering ratio from ALC in Aosta-Saint-Christophe. Arrows: horizontal velocity of the wind measured at the surface and simulated by COSMO at several elevations. (b) Vertical profile of relative humidity forecasted by COSMO. (c) Vertical profile of $\mathrm{PM}_{10}$ mass concentration derived from the ALC using the functional relationships. (d) Mass concentration $\left(\mathrm{PM}_{10 \mathrm{w}}\right)$ from FARM. (e) Hourly and sub-hourly $\mathrm{PM}_{10}$ (dry) surface concentration from FARM simulations and observations in Aosta-Saint-Christophe and Aosta-downtown. 


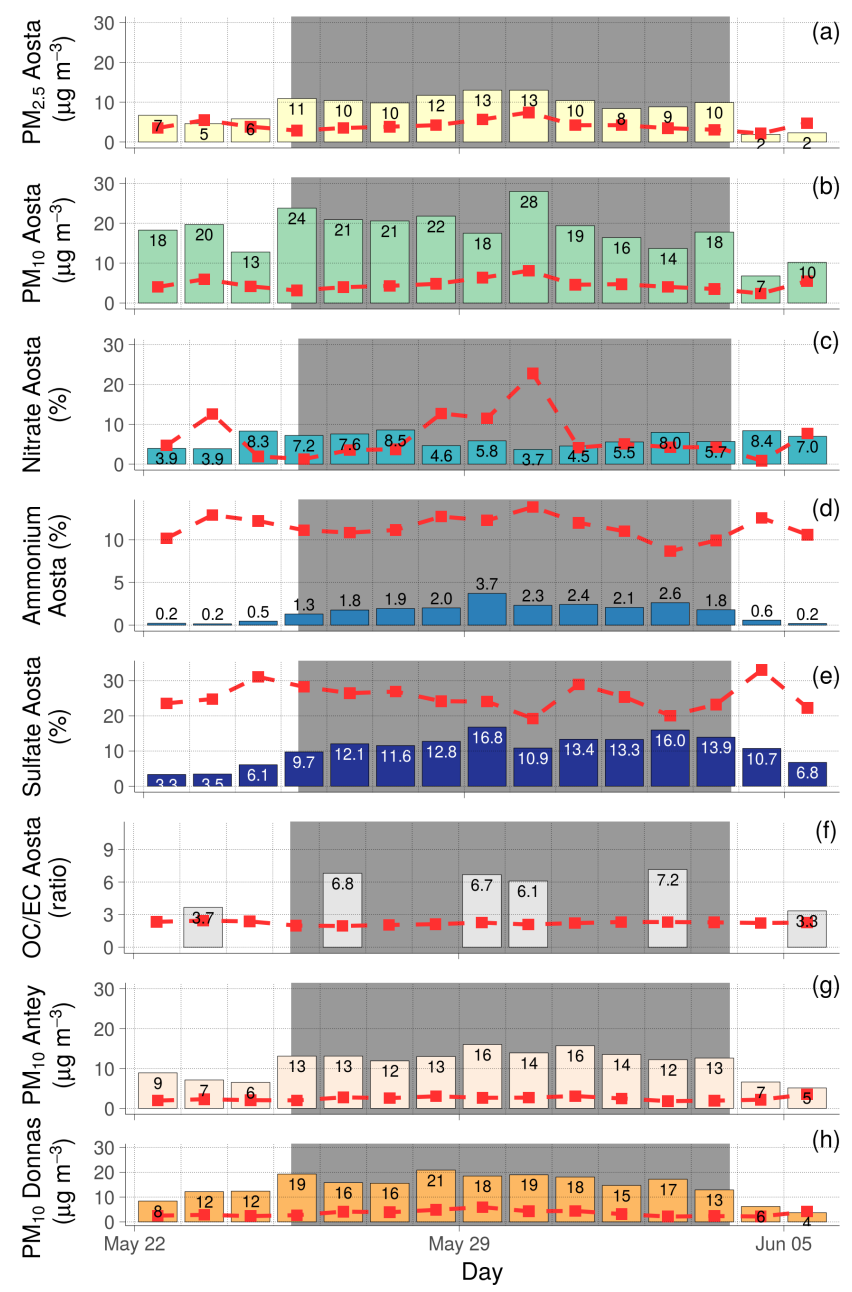

Figure 13. Measured (coloured bars) and simulated (dotted line) $\mathrm{PM}_{2.5}$ and $\mathrm{PM}_{10}$ concentrations at several sites of the Aosta Valley $(\mathbf{a}, \mathbf{b}, \mathbf{g}, \mathbf{h})$; percentage concentrations of nitrate (c), ammonium (d), and sulfate (e) and OC/EC ratio (f) at Aosta-downtown during case study 3 (May-June 2017). The period when the ALC detects a thick layer above Aosta-Saint-Christophe is highlighted with a grey background.

6.1-7.2) compared to the value before (3.7) and after (3.3) the event. This increase in the $\mathrm{OC}$ fraction during transport episodes is confirmed by the long-term analysis (Diémoz et al., 2019).

\subsubsection{Sun photometer measurements}

The same morning-midday-afternoon modulation can be observed in the AOD from both the ALC and the sun photometer (Fig. S9e). The high AOD values in the first and last part of the day (up to $0.30-0.40$ at $500 \mathrm{~nm}$ ) and the decrease in the middle of the day (down to 0.12 at $500 \mathrm{~nm}$ ) match the appearance of the layer seen by the ALC and its enhancement due to hygroscopic effects, in accordance with the results of Adam et al. (2012) for a typical site in the Po basin (in that case, for RH $=90 \%$, the extinction coefficient increased on average to $180 \%$ of the value measured for $\mathrm{RH}=0 \%$ ). The steep rise (from 0.8 to 1.7) in the Ångström exponent on 25 May (Fig. S9f) and its continuous increase in the following days (up to nearly 2.0) may be attributed to the advection of small particles to the measuring site. The SSA fluctuates around large values (generally between 0.9 and 1.0), typical of weakly light-absorbing or aged aerosol. Most interestingly, the volume distribution (Fig. S9g) exhibits an abrupt decrease in the peak diameter during the morning hours (e.g. from $0.5 \mu \mathrm{m}$ at $06: 40 \mathrm{UTC}$ to $0.2 \mu \mathrm{m}$ at midday on 27 May), strengthening the hypothesis of aerosol hydration at night and dehydration during the day as temperature increases and RH decreases.

\subsection{Model-measurement discrepancies}

Our CTM qualitatively reproduces the aerosol advection in all three case studies. It helps to understand the phenomenon by allowing us to switch the non-local sources on or off (boundary conditions) but fails to quantitatively explain the concentrations retrieved by the ALC $\left(\mathrm{PM}_{10 \mathrm{w}}\right)$ and measured by the air quality network $\left(\mathrm{PM}_{10}\right)$. As already mentioned in the description of the three cases, the model (a) underestimates the PM mass both in the layer aloft and at the surface and (b) anticipates the peak concentrations compared to the profiles from the ALC. A variety of (possibly concurrent) reasons can explain the observed underestimation, mainly related to the following.

1. Inaccuracies in retrieving the PM concentration from the ALC backscatter can lead to overestimation in the ALC-determined PM. As mentioned, ALC measures aerosol backscatter, so that specific tools were developed (Dionisi et al., 2018) and are used here to associate a PM value with it. Still, the expected error associated with these estimates is of the order of $30 \%-$ $40 \%$. In addition, the ALC retrieval is based on functional relationships derived assuming a maximum $\mathrm{RH}$ of $95 \%$. Higher FARM-ALC discrepancies can be expected when $\mathrm{RH}>\mathrm{DRH}$, and particularly at $\mathrm{RH}>$ $95 \%$;

2. Inaccuracies in the CTM simulations can lead to underestimation in the simulated PM. The emission inventory used within FARM likely underestimates the real emissions, as also reported in other cases, and for different models, in the scientific literature (e.g. EMEP, 2016; Uchino et al., 2017). In particular, the boundary conditions could not be accurate enough for our aims owing to the abrupt change of the national emission inventory grid resolution $(12 \mathrm{~km})$ to the local scale $(1 \mathrm{~km})$. This issue can affect the comparison between the model (dry $\mathrm{PM}_{10}$ ) and surface measurements, especially in winter, as discussed more extensively in the companion paper (Diémoz et al., 2019). Additionally, 
the aerosol hygroscopicity may not be optimally simulated by FARM, e.g. due to a wrong characterisation of the chemical properties of the modelled aerosol, which again impacts the comparison between the vertical profiles from the model and the ALC. Finally, some underestimation of PM values could also be due to overestimation of the FARM-simulated PBL height. An evaluation of this kind of effect is in principle possible by comparing the simulations with the ALC-derived PBL height (e.g. Angelini et al., 2009; Haeffelin et al., 2012). However, this should be performed only selecting nonadvection conditions, i.e. those in which the ceilometer signal is only affected by local aerosols and is thus able to follow the daily evolution of the local PBL using local particles as tracers. This kind of investigation was, however, beyond the scope of the present work. Challenges and recent efforts to define a PBL in mountainous areas ("mountain boundary layer", MBL) and discrepancies between the MBL and the aerosol layer are more extensively described by Lehner and Rotach (2018).

The case studies described here show that several of the previous points most likely play a significant role. Some sensitivity tests were performed addressing point 2 . In particular, for the first case study (August 2015, Sect. 4.1) we performed two additional tests. (1) We doubled the PM concentrations from the boundary conditions to assess the sensitivity of the simulated vertical profiles to the accuracy of the national emission inventory and to the transport from outside the administrative boundaries of the Aosta Valley, while leaving the regional emission inventory unchanged. The perturbation of the boundary conditions used for the test may appear excessively large; however this choice could be supported by the fact that the resolution of the national inventory grid is much coarser than the local one, which may be a source of inaccuracies. (2) We employed two different, more empirical parametrisations of the aerosol hygroscopicity to recalculate water uptake by aerosol. As shown in the Supplement (Sect. S7), the results of the two tests support the hypothesis that both the national inventory and the parametrisation of the hygroscopic effects in the model are responsible for the discrepancies between simulations and measurements in the first case study. Doubling the boundary conditions also slightly improves the comparison between simulations and measurements at the surface for the winter case study (first introduced in Sect. 4.2), although some discrepancies in the geographic distribution of the concentrations persist (Fig. S12, e.g. overestimation on 25 January 2017 and underestimation on the following days), probably due to inaccurate NWP input data. Finally, it is worth mentioning that, during the winter episode, a small fraction of the detected secondary particulate might form locally due to heterogeneous chemical reactions taking place on the advected particles themselves (e.g. Gilardoni et al., 2016; Kim et al., 2018; Lim et al., 2018). These dynamics could contribute to the observed underestimation; however they are too complex to be simulated by present CTMs. Further efforts on this topic are scheduled for the future.

The previous considerations, however, fail at comprehensively explaining the time shifts sometimes noticeable between the model and the measurements, i.e. anticipation of the advection arrival time (even in "dry" conditions in the afternoon on the first day of each sequence) and of the layer disappearance in the morning (in which hygroscopicity may have an important role). Although an accurate assessment would require a more sophisticated set of instruments to characterise the vertical profile of the wind velocity, here we formulate some hypotheses.

1. The NWP model likely anticipates and overestimates the easterly thermally driven winds in the first hours of the afternoon. This is noticeable, for example, in Fig. S13, in which the zonal component of the wind from both COSMO and the surface measurements for case study 1 (August 2015) is plotted, and, on a longer statistical basis, in Fig. S1b, c, showing that the model has the tendency to see easterly winds more often and with higher intensity compared to the observations. A possible reason for that is the smoothed valley orography used in the NWP model compared to the real one. This is displayed in Fig. S14, showing the difference of the digital elevation model (DEM) used within COSMO and a more realistic DEM (10 m resolution): both valleys and mountain crests are clearly smoothed out by COSMO, with absolute differences well $>500 \mathrm{~m}$ (and up to $1000 \mathrm{~m}$ ). This difference could additionally explain why the altitude of the entrainment zone (i.e. the boundary between the free atmosphere and the boundary layer where the thermally driven circulation develops) is underestimated by COSMO compared to the height of the aerosol layer detected by the ALC (e.g. Figs. 3 and 12).

2. COSMO overestimates the nighttime drainage winds (katabatic winds), as noticeable, again, from Fig. S13 for case study 1 . This might trigger enhanced cleansing of the lower atmospheric layers during the night as simulated by FARM (see, e.g. the Supplement video file relative to Fig. 6, https://doi.org/10.5446/38391), but undetected by the ALC. An overestimation of the drainage winds would also explain the differences between the simulated and measured daily cycle of $\mathrm{SH}$, represented in Fig. S15 for case study 1 as an example. In fact, the measured SH usually increases during the first advection day as a result of the transport from source areas with more stagnating conditions (cf. Figs. 3, 9, and 12) but stays rather constant for the rest of the episode. Conversely, COSMO yields larger dynamics, with SH maxima in the late afternoon and a subsequent decrease, likely owing to overestimated drainage winds develop- 
ing after sunset (this results in a $\mathrm{SH}$ minimum in the late morning).

As a final remark, we also mention that the $2.8 \mathrm{~km}$ grid resolution of the COSMO-I2 model might still be insufficient for resolving the complex 3-D flow field of an Alpine valley and is too coarse to reproduce the mountain atmosphere with its various mixing processes. Follow-up studies using next-generation NWP models with increased resolution (1 km or lower) would be of great interest. Conversely it should also be noticed that decreasing the grid spacing below the scale for which turbulence parametrisations have been developed, i.e. modelling the "grey zone" (or "terra incognita"; e.g. Wyngaard, 2004), does not necessarily lead to better performances. In this context, comparison of high-resolution simulations with our vertically resolved dataset could represent a challenging future benchmark for this relevant topic of ongoing research.

\section{Conclusions}

We investigated the phenomenology of recurrent episodes of wind-driven arrival of aerosol layers in the northwestern Italian Alps, and specifically in the Aosta Valley. The analysis was performed by combining a multiple-site, multiple-sensor measurement dataset with modelling tools. Through a deep examination of three case studies, specifically selected within a 3-year dataset as clear examples of the phenomenon under investigation, we can provide the following answers to the scientific questions driving the study (see Introduction).

1. What is the origin of the aerosol layers detected in the northwestern Alps?

All results agreed in showing these episodes to be associated with the arrival of polluted air masses originating from the Po basin, one of the European pollution hotspots. To reach this conclusion, we examined wind flows from both the experimental (surface observations of the wind velocity from the meteorological network at multiple elevations) and modelling (high-resolution NWP models, back trajectories, and CTM simulations) perspectives. Interestingly, in one case (Sect. 4.2.2), calm wind measurements at the bottom of the valley in cold-pool conditions at the beginning of the advection episode could give the mistaken impression that the aerosol originated from local sources since the circulation in the lowermost levels was inactive, while the wind was blowing undisturbed above the temperature inversion. However, the ALC capacities of sounding the vertical profile of the atmosphere, together with the experimental and modelling data at different elevations, turned out to be a substantial benefit for the clear understanding of the phenomenon.

2. What conditions are favourable to the aerosol flow into the valley?
We show that these advections are due to thermally driven winds (especially in the warm period of the year, e.g. case studies 1 and 3 ) or synoptic flows (mainly in the cold season, e.g. case 2) from the east (Po basin) to the west. A more systematic analysis of the flow regimes and their impacts on transport based on comprehensive statistics are provided in the companion paper (Diémoz et al., 2019) exploiting the full 3-year record of ALC measurements. These show that conditions favourable for the development of the advections occur on $>50 \%$ of the days on average. Also, we expect the frequency of the advections to increase with increasing proximity to the source (Po basin).

3. How do the advected aerosol layers evolve in both altitude and time?

Thanks to the monitoring capacity (24/7) of the ALCs, we could follow the evolution of the aerosol layer in both altitude and time. We show that the advected aerosol layers can extend up to $4000 \mathrm{~m}$ a.s.l. in the warm season, which incidentally points out the potential impacts of aerosol dry and wet depositions on the remote high-altitude ecosystems. Conversely, the altitude of the layer sounded by the ALC is a clear indication that the emissions are not local. As for the evolution in time, the layers were usually detected to arrive over Aosta in the afternoon, when the plain-mountain thermal regime is established. However, the backscatter from the ALC was found to reach its maximum during the night, when water uptake on aerosol took place and clouds could frequently form within the aerosol layer.

4. What is the impact of the transported aerosol on PM surface concentrations and chemical composition?

An important increase in $\mathrm{PM}_{10}$ and $\mathrm{PM}_{2.5}$ was detectable during the investigated advections, with up to $80 \mu \mathrm{g} \mathrm{m}^{-3}$ of $\mathrm{PM}_{10}$ likely transported in Donnas (Fig. 11). The size distribution of the advected particles generally peaks in the accumulation mode, with a diameter of a few tenths of a micrometre (as observed by both the OPC, at the surface, and the sun photometer, in the uppermost layers). Moreover, this kind of particulate is weakly light-absorbing (sun photometer). Chemical analyses reveal these layers to produce an increase in the secondary inorganic fraction, composed by nitrate, sulfate, and ammonium, i.e. three typical compounds found in the Po Valley atmosphere, and with low deliquescence RH. Weak local formation of secondary particulate could not be excluded during episodes of severe advection (e.g. case study 2), probably also due to aqueous phase chemistry. However, including these latter processes in current CTMs is still challenging. In one of the case studies, the $\mathrm{OC} / \mathrm{EC}$ ratio was also observed to increase, a possible sign of the transport of organic compounds from the Po basin. 
5. Are the presently used CTMs able to reproduce and explain the observations along the vertical profile?

Our investigation allowed an evaluation of the FARM model. Notably, FARM could reproduce the observed arrival of elevated aerosol layers and it correctly attributed them to sources external to the Aosta Valley. However, absolute values of PM concentrations and the timing of the advections were poorly reproduced, with underestimations of aerosol concentrations and time anticipations compared to the measurements. On the basis of a sensitivity study, the former issue may be partly attributed to both water uptake by highly hygroscopic particles, not fully taken into account in the model, and deficiencies in the emission inventories, especially owing to the coarse resolution of the national one $(12 \mathrm{~km})$. As for the timing discrepancies, suboptimal performances of the NWP model to simulate daytime (thermally driven) and nighttime (katabatic) winds are the most likely sources of error. Despite these limitations, FARM brought insights into the phenomenology addressed, supporting the observations and helping to interpret them. Conversely, the observation-based results of this work could drive the improvement of the emission inventories, thus enhancing the reliability of the CTM (e.g. Diémoz et al., 2019). In turn, this could allow the extension of the findings of this work to a wider domain, not covered (or not fully covered) by observations.

The phenomenology described in detail in the current study through the selected cases has been further investigated in the companion paper, exploiting the complete observational dataset over the period 2015-2017, complemented by a long-term simulation by the FARM model. This wider dataset, inspected by statistical techniques and classification schemes, allowed a quantitative evaluation of the long-term impact of the aerosol transported from the Po basin to the air quality in the northwestern Alps. Still, future work is needed to investigate possible local and basin-wide strategies to effectively mitigate this impact.

Data availability. The ALC data are available upon request to the ALICEnet (alicenet@ isac.cnr.it) and E-PROFILE (http://data.ceda. ac.uk/badc/eprofile/data/; E-PROFILE, 2019) networks. The sun photometer data can be downloaded from the EuroSkyRad network web site (http://www.euroskyrad.net/index.html; EuroSkyRad, 2019) after authentication (credentials may be requested from Monica Campanelli, m.campanelli@isac.cnr.it). The measurements from the ARPA air quality surface network are available at the web page http://www.arpa.vda.it/it/aria/la-qualità-dell-aria/stazioni-dimonitoraggio/inquinanti-export-dati (ARPA Valle d'Aosta, 2019). The wind data in Milan refer to the ClimateNetwork ${ }^{\circledR}$ weather station Milan Bicocca and were kindly provided by Fondazione OMD. The weather data from the Aosta-Saint-Christophe and Saint-Denis stations can be retrieved from http://cf.regione.vda.it/richiesta_dati. php (last access: 28 February 2019) upon request to Centro Funzionale della Valle d'Aosta. The MAIAC data were made available by Alexei Lyapustin (NASA). The rest of the data can be requested from the corresponding author (h.diemoz@arpa.vda.it).

Video supplement. Video file (https://doi.org/10.5446/38391; Diémoz, 2018) showing the simulated 4-D evolution of PM concentrations over the Aosta Valley (a snapshot being provided in Fig. 6).

Supplement. The supplement related to this article is available online at: https://doi.org/10.5194/acp-19-3065-2019-supplement.

Author contributions. HD, FB, and GPG conceived and designed the study and contributed to the interpretation of the results. TM supplied the meteorological observations and numerical weather predictions. GP performed the chemical transport simulations. DD provided the ALC functional relationships and assistance on the Rayleigh ALC calibration with inputs from MH. SP carried out the EC/OC analyses and IKFT helped with the interpretation of the chemical speciation. MC supplied the POM calibration factors. FB and LDC prepared the satellite radiometer data. LDL and LF provided the ALC data from Milan. HD analysed the data and wrote the paper with contributions from FB, GPG, and all co-authors.

Competing interests. The authors declare that they have no conflict of interest.

Special issue statement. This article is part of the special issue "SKYNET - the international network for aerosol, clouds, and solar radiation studies and their applications (AMT/ACP inter-journal SI)". It is not associated with a conference.

Acknowledgements. The authors would like to thank Alessandra Brunier, Giuliana Lupato, Paolo Proment, Stefania Vaccari, and Maria Cristina Gibellino (ARPA Valle d'Aosta) for carrying out the chemical analyses; Marco Pignet, Claudia Tarricone, and Manuela Zublena (ARPA Valle d'Aosta) for providing the data from the air quality surface network; Fondazione OMD and Centro Funzionale della Valle d'Aosta for the additional meteorological series; Alexei Lyapustin (NASA) for the MAIAC data; and Silvia Ferrarese (Turin University) for the exchange about high-resolution models in the "terra incognita" regime. The authors would like to acknowledge the valuable contribution of the discussions in the working group meetings organised by COST Action ES1303 (TOPROF). They also gratefully acknowledge the Institute for Atmospheric and Climate Science, ETH Zurich, Switzerland, for the provision of the LAGRANTO software used in this publication. The contribution of Luca Ferrero is an outcome of the GEMMA Center, in the framework of Project MIUR Dipartimenti di Eccellenza 2018-2022. 
Edited by: Stelios Kazadzis

Reviewed by: four anonymous referees

\section{References}

Adam, M., Putaud, J. P., Martins dos Santos, S., Dell'Acqua, A., and Gruening, C.: Aerosol hygroscopicity at a regional background site (Ispra) in Northern Italy, Atmos. Chem. Phys., 12, 57035717, https://doi.org/10.5194/acp-12-5703-2012, 2012.

Agnesod, G., Moulin, P.-A., Pession, G., Villard, H., and Zublena, M.: Étude Air Espace Mont-Blanc - Rapport Technique, Tech. rep., Espace Mont Blanc, available at: http://www.arpa.vda.it/images/stories/ARPA/aria/progetti/ progairmb_agnesod_2003.pdf (last access: 28 February 2019), 2003.

Aksoyoglu, S., Ciarelli, G., El-Haddad, I., Baltensperger, U., and Prévôt, A. S. H.: Secondary inorganic aerosols in Europe: sources and the significant influence of biogenic VOC emissions, especially on ammonium nitrate, Atmos. Chem. Phys., 17, 77577773, https://doi.org/10.5194/acp-17-7757-2017, 2017.

Anfossi, D., Cassardo, C., Giraud, C., Longhetto, A., Villone, B., Bacci, P., Bonelli, P., Carboni, G., Bonafè, U., Bonasoni, P., and Giovanelli, G.: Experimental study of transalpine transport of trace effluents: a comparison with synoptic trajectories of airflow, Nuovo Cimento C, 11, 489-526, https://doi.org/10.1007/BF02506997, 1988.

Angelini, F., Barnaba, F., Landi, T. C., Caporaso, L., and Gobbi, G. P.: Study of atmospheric aerosols and mixing layer by LIDAR, Radiat. Prot. Dosim., 137, 275-279, https://doi.org/10.1093/rpd/ncp219, 2009.

Ångström, A.: On the Atmospheric Transmission of Sun Radiation and on Dust in the Air, Geogr. Ann., 11, 156-166, 1929.

ARPA Valle d'Aosta: Air quality data, available at: http://www.arpa.vda.it/it/aria/la-qualità-dell-aria/stazioni-dimonitoraggio/inquinanti-export-dati, last access: 7 March 2019.

Bacco, D., Trentini, A., Minguzzi, E., Amorati, R., Zigola, C., Deserti, M., and Poluzzi, V.: Chimica del particolato e meteo, un'analisi sul campo, Ecoscienza, 1, available at: https://www.arpae.it/cms3/documenti/_cerca_doc/ecoscienza/ ecoscienza2017_1/bacco_et_al_es2017_01.pdf (last access: 28 February 2019), 2017.

Baldauf, M., Seifert, A., Förstner, J., Majewski, D., Raschendorfer, M., and Reinhardt, T.: Operational Convective-Scale Numerical Weather Prediction with the COSMO Model: Description and Sensitivities, Mon. Weather Rev., 139, 3887-3905, https://doi.org/10.1175/MWR-D-10-05013.1, 2011.

Barnaba, F. and Gobbi, G. P.: Lidar estimation of tropospheric aerosol extinction, surface area and volume: Maritime and desert-dust cases, J. Geophys. Res., 106, 3005-3018, https://doi.org/10.1029/2000JD900492, 2001.

Barnaba, F. and Gobbi, G. P.: Modeling the Aerosol Extinction versus Backscatter Relationship for Lidar Applications: Maritime and Continental Conditions, J. Atmos. Ocean. Tech., 21, 428-442, https://doi.org/10.1175/15200426(2004)021<0428:MTAEVB>2.0.CO;2, 2004.

Barnaba, F., Gobbi, G. P., and de Leeuw, G.: Aerosol stratification, optical properties and radiative forcing in Venice
(Italy) during ADRIEX, Q. J. Roy. Meteor. Soc., 133, 47-60, https://doi.org/10.1002/qj.91, 2007.

Barnaba, F., Putaud, J. P., Gruening, C., dell'Acqua, A., and Dos Santos, S.: Annual cycle in co-located in situ, total-column, and height-resolved aerosol observations in the Po Valley (Italy): Implications for ground-level particulate matter mass concentration estimation from remote sensing, J. Geophys. Res., 115, D19209, https://doi.org/10.1029/2009JD013002, 2010.

Belis, C., Blond, N., Bouland, C., Carnevale, C., Clappier, A., Douros, J., Fragkou, E., Guariso, G., Miranda, A. I., Nahorski, Z., Pisoni, E., Ponche, J.-L., Thunis, P., Viaene, P., and Volta, M.: Strengths and Weaknesses of the Current EU Situation, Springer International Publishing, 69-83, https://doi.org/10.1007/978-3319-33349-6_4, 2017.

Bigi, A. and Ghermandi, G.: Trends and variability of atmospheric $\mathrm{PM}_{2.5}$ and $\mathrm{PM}_{10-2.5}$ concentration in the Po Valley, Italy, Atmos. Chem. Phys., 16, 15777-15788, https://doi.org/10.5194/acp-16-15777-2016, 2016.

Binkowski, F.: Science Algorithms of the EPA Models-3 Community Multiscale Air Quality (CMAQ) Modeling System, vol. EPA/600/R-99/030, chap. The aerosol portion of Models-3 CMAQ, edited by: Byun, D. W. and Ching, J. K. S., 1999.

Birch, M. E. and Cary, R. A.: Elemental Carbon-Based Method for Monitoring Occupational Exposures to Particulate Diesel Exhaust, Aerosol Sci. Tech., 25, 221-241, https://doi.org/10.1080/02786829608965393, 1996.

Borghi, S. and Giuliacci, M.: Circulation features driven by diurnal heating in the lower atmospheric layers of the Po Valley, Nuovo Cimento C, 3, 1-16, https://doi.org/10.1007/BF02509187, 1980.

Bourgeois, I., Savarino, J., Caillon, N., Angot, H., Barbero, A., Delbart, F., Voisin, D., and Clément, J.-C.: Tracing the Fate of Atmospheric Nitrate in a Subalpine Watershed Using $\Delta^{17} \mathrm{O}$, Environ. Sci. Technol., 52, 5561-5570, https://doi.org/10.1021/acs.est.7b02395, 2018.

Bucci, S., Cristofanelli, P., Decesari, S., Marinoni, A., Sandrini, S., Größ, J., Wiedensohler, A., Di Marco, C. F., Nemitz, E., Cairo, F., Di Liberto, L., and Fierli, F.: Vertical distribution of aerosol optical properties in the Po Valley during the 2012 summer campaigns, Atmos. Chem. Phys., 18, 5371-5389, https://doi.org/10.5194/acp-18-5371-2018, 2018.

Burkhardt, J., Zinsmeister, D., Grantz, D. A., Vidic, S., Sutton, M. A., Hunsche, M., and Pariyar, S.: Camouflaged as degraded wax: hygroscopic aerosols contribute to leaf desiccation, tree mortality, and forest decline, Environ. Res. Lett., 13, 085001, https://doi.org/10.1088/1748-9326/aad346, 2018.

Calori, G., Silibello, C., and Marras, G.: FARM (Flexible Air quality Regional Model) Model formulation and user's Manual, Arianet, 4.7 Edn., 2014.

Campanelli, M., Estellés, V., Tomasi, C., Nakajima, T., Malvestuto, V., and Martínez-Lozano, J. A.: Application of the SKYRAD Improved Langley plot method for the in situ calibration of CIMEL Sun-sky photometers, Appl. Optics, 46, 2688-2702, https://doi.org/10.1364/AO.46.002688, 2007.

Campanelli, M., Mascitelli, A., Sanò, P., Diémoz, H., Estellés, V., Federico, S., Iannarelli, A. M., Fratarcangeli, F., Mazzoni, A., Realini, E., Crespi, M., Bock, O., Martínez-Lozano, J. A., and Dietrich, S.: Precipitable water vapour content from ESR/SKYNET sun-sky radiometers: validation against GNSS/GPS and AERONET over three different sites in Europe, 
Atmos. Meas. Tech., 11, 81-94, https://doi.org/10.5194/amt-1181-2018, 2018.

Carbone, C., Decesari, S., Mircea, M., Giulianelli, L., Finessi, E., Rinaldi, M., Fuzzi, S., Marinoni, A., Duchi, R., Perrino, C., Sargolini, T., Vardè, M., Sprovieri, F., Gobbi, G., Angelini, F., and Facchini, M.: Size-resolved aerosol chemical composition over the Italian Peninsula during typical summer and winter conditions, Atmos. Environ., 44, 5269-5278, https://doi.org/10.1016/j.atmosenv.2010.08.008, 2010.

Carbone, C., Decesari, S., Paglione, M., Giulianelli, L., Rinaldi, M., Marinoni, A., Cristofanelli, P., Didiodato, A., Bonasoni, P., Fuzzi, S., and Facchini, M. C.: 3-year chemical composition of free tropospheric $\mathrm{PM}_{1}$ at the Mt. Cimone GAW global station - South Europe - 2165 m a.s.1., Atmos. Environ., 87, 218-227, https://doi.org/10.1016/j.atmosenv.2014.01.048, 2014.

Carslaw, K. S., Boucher, O., Spracklen, D. V., Mann, G. W., Rae, J. G. L., Woodward, S., and Kulmala, M.: A review of natural aerosol interactions and feedbacks within the Earth system, Atmos. Chem. Phys., 10, 1701-1737, https://doi.org/10.5194/acp10-1701-2010, 2010.

Carter, W.: Documentation of the SAPRC-99 Chemical Mechanism for VOC Reactivity Assessment. Final Report to California Air Resources Board, Contract 92-329 and 95-308, SAPRC, Tech. rep., University of California, Riverside, CA, available at: http://www.engr.ucr.edu/ carter/pubs/s99doc.pdf (last access: 28 February 2019), 2000.

Caserini, S., Giani, P., Cacciamani, C., Ozgen, S., and Lonati, G.: Influence of climate change on the frequency of daytime temperature inversions and stagnation events in the Po Valley: historical trend and future projections, Atmos. Res., 184, 15-23, https://doi.org/10.1016/j.atmosres.2016.09.018, 2017.

Cavalli, F., Viana, M., Yttri, K. E., Genberg, J., and Putaud, J.-P.: Toward a standardised thermal-optical protocol for measuring atmospheric organic and elemental carbon: the EUSAAR protocol, Atmos. Meas. Tech., 3, 79-89, https://doi.org/10.5194/amt-3-792010, 2010.

Cesaroni, G., Badaloni, C., Gariazzo, C., Stafoggia, M., Sozzi, R., Davoli, M., and Forastiere, F.: Long-term exposure to urban air pollution and mortality in a cohort of more than a million adults in Rome, Environ. Health Persp., 121, 324-331, https://doi.org/10.1289/ehp.1205862, 2013.

Charron, A., Harrison, R. M., Moorcroft, S., and Booker, J.: Quantitative interpretation of divergence between $\mathrm{PM}_{10}$ and $\mathrm{PM}_{2.5}$ mass measurement by TEOM and gravimetric (Partisol) instruments, Atmos. Environ., 38, 415-423, https://doi.org/10.1016/j.atmosenv.2003.09.072, 2004.

Chu, D. A., Kaufman, Y. J., Zibordi, G., Chern, J. D., Mao, J., Li, C., and Holben, B. N.: Global monitoring of air pollution over land from the Earth Observing System-Terra Moderate Resolution Imaging Spectroradiometer (MODIS), J. Geophys. Res., 108, 4661, https://doi.org/10.1029/2002JD003179, 2003.

Chudnovsky, A. A., Koutrakis, P., Kloog, I., Melly, S., Nordio, F., Lyapustin, A., Wang, Y., and Schwartz, J.: Fine particulate matter predictions using high resolution Aerosol Optical Depth (AOD) retrievals, Atmos. Environ., 89, 189-198, https://doi.org/10.1016/j.atmosenv.2014.02.019, 2014.

Clerici, M. and Mélin, F.: Aerosol direct radiative effect in the Po Valley region derived from AERONET measurements, Atmos.
Chem. Phys., 8, 4925-4946, https://doi.org/10.5194/acp-8-49252008, 2008.

Collaud Coen, M., Andrews, E., Aliaga, D., Andrade, M., Angelov, H., Bukowiecki, N., Ealo, M., Fialho, P., Flentje, H., Hallar, A. G., Hooda, R., Kalapov, I., Krejci, R., Lin, N.-H., Marinoni, A., Ming, J., Nguyen, N. A., Pandolfi, M., Pont, V., Ries, L., Rodríguez, S., Schauer, G., Sellegri, K., Sharma, S., Sun, J., Tunved, P., Velasquez, P., and Ruffieux, D.: Identification of topographic features influencing aerosol observations at high altitude stations, Atmos. Chem. Phys., 18, 12289-12313, https://doi.org/10.5194/acp-18-12289-2018, 2018.

Cong, Z., Kawamura, K., Kang, S., and Fu, P.: Penetration of biomass-burning emissions from South Asia through the Himalayas: new insights from atmospheric organic acids, Sci. Rep.UK, 5, 9580, https://doi.org/10.1038/srep09580, 2015.

Cristofanelli, P., Marinoni, A., Arduini, J., Bonafè, U., Calzolari, F., Colombo, T., Decesari, S., Duchi, R., Facchini, M. C., Fierli, F., Finessi, E., Maione, M., Chiari, M., Calzolai, G., Messina, P., Orlandi, E., Roccato, F., and Bonasoni, P.: Significant variations of trace gas composition and aerosol properties at $\mathrm{Mt}$. Cimone during air mass transport from North Africa - contributions from wildfire emissions and mineral dust, Atmos. Chem. Phys., 9, 4603-4619, https://doi.org/10.5194/acp-9-4603-2009, 2009.

Cugerone, K., De Michele, C., Ghezzi, A., Gianelle, V., and Gilardoni, S.: On the functional form of particle number size distributions: influence of particle source and meteorological variables, Atmos. Chem. Phys., 18, 4831-4842, https://doi.org/10.5194/acp-18-4831-2018, 2018.

Curci, G., Ferrero, L., Tuccella, P., Barnaba, F., Angelini, F., Bolzacchini, E., Carbone, C., Denier van der Gon, H. A. C., Facchini, M. C., Gobbi, G. P., Kuenen, J. P. P., Landi, T. C., Perrino, C., Perrone, M. G., Sangiorgi, G., and Stocchi, P.: How much is particulate matter near the ground influenced by upperlevel processes within and above the PBL? A summertime case study in Milan (Italy) evidences the distinctive role of nitrate, Atmos. Chem. Phys., 15, 2629-2649, https://doi.org/10.5194/acp15-2629-2015, 2015.

D’Angelo, L., Rovelli, G., Casati, M., Sangiorgi, G., Perrone, M. G., Bolzacchini, E., and Ferrero, L.: Seasonal behavior of $\mathrm{PM}_{2.5}$ deliquescence, crystallization, and hygroscopic growth in the Po Valley (Milan): Implications for remote sensing applications, Atmos. Res., 176-177, 87-95, https://doi.org/10.1016/j.atmosres.2016.02.011, 2016.

Decesari, S., Allan, J., Plass-Duelmer, C., Williams, B. J., Paglione, M., Facchini, M. C., O’Dowd, C., Harrison, R. M., Gietl, J. K., Coe, H., Giulianelli, L., Gobbi, G. P., Lanconelli, C., Carbone, C., Worsnop, D., Lambe, A. T., Ahern, A. T., Moretti, F., Tagliavini, E., Elste, T., Gilge, S., Zhang, Y., and Dall'Osto, M.: Measurements of the aerosol chemical composition and mixing state in the Po Valley using multiple spectroscopic techniques, Atmos. Chem. Phys., 14, 12109-12132, https://doi.org/10.5194/acp-1412109-2014, 2014.

de Freitas, C. R.: Tourism climatology: evaluating environmental information for decision making and business planning in the recreation and tourism sector, Int. J. Biometeorol., 48, 45-54, https://doi.org/10.1007/s00484-003-0177-z, 2003.

Della Ceca, L., García Ferreyra, M. F., Lyapustin, A., Chudnovsky, A., Otero, L., Carreras, H., and Barnaba, F.: Satellitebased view of the aerosol spatial and temporal variability 
in the Córdoba region (Argentina) using over ten years of high-resolution data, ISPRS J. Photogramm., 145, 250-267, https://doi.org/10.1016/j.isprsjprs.2018.08.016, 2018.

De Wekker, S. F. J., Kossmann, M., Knievel, J. C., Giovannini, L., Gutmann, E. D., and Zardi, D.: Meteorological Applications Benefiting from an Improved Understanding of Atmospheric Exchange Processes over Mountains, Atmosphere, 9, 371, https://doi.org/10.3390/atmos9100371, 2018.

Dhungel, S., Kathayat, B., Mahata, K., and Panday, A.: Transport of regional pollutants through a remote trans-Himalayan valley in Nepal, Atmos. Chem. Phys., 18, 1203-1216, https://doi.org/10.5194/acp-18-1203-2018, 2018.

Diémoz, H.: 4-D CTM simulation of aerosol advections from the Po basin to the northwestern Alps, https://doi.org/10.5446/38391, 2018.

Diémoz, H., Siani, A. M., Casale, G. R., di Sarra, A., Serpillo, B., Petkov, B., Scaglione, S., Bonino, A., Facta, S., Fedele, F., Grifoni, D., Verdi, L., and Zipoli, G.: First national intercomparison of solar ultraviolet radiometers in Italy, Atmos. Meas. Tech., 4, 1689-1703, https://doi.org/10.5194/amt-4-1689-2011, 2011.

Diémoz, H., Campanelli, M., and Estellés, V.: One Year of Measurements with a POM-02 Sky Radiometer at an Alpine EuroSkyRad Station, J. Meteorol. Soc. Jpn., 92A, 1-16, https://doi.org/10.2151/jmsj.2014-A01, 2014a.

Diémoz, H., Siani, A. M., Redondas, A., Savastiouk, V., McElroy, C. T., Navarro-Comas, M., and Hase, F.: Improved retrieval of nitrogen dioxide $\left(\mathrm{NO}_{2}\right)$ column densities by means of MKIV Brewer spectrophotometers, Atmos. Meas. Tech., 7, 4009-4022, https://doi.org/10.5194/amt-7-4009-2014, 2014b.

Diémoz, H., Gobbi, G. P., Magri, T., Pession, G., Pittavino, S., Tombolato, I. K. F., Campanelli, M., and Barnaba, F.: Transport of Po Valley aerosol pollution to the northwestern Alps. Part 2: long-term impact on air quality, Atmos. Chem. Phys. Discuss., submitted, 2019.

Dionisi, D., Barnaba, F., Diémoz, H., Di Liberto, L., and Gobbi, G. P.: A multiwavelength numerical model in support of quantitative retrievals of aerosol properties from automated lidar ceilometers and test applications for AOT and $\mathrm{PM}_{10}$ estimation, Atmos. Meas. Tech., 11, 6013-6042, https://doi.org/10.5194/amt11-6013-2018, 2018.

Dosio, A., Galmarini, S., and Graziani, G.: Simulation of the circulation and related photochemical ozone dispersion in the Po plains (northern Italy): Comparison with the observations of a measuring campaign, J. Geophys. Res., 107, LOP 2-1-LOP 224, https://doi.org/10.1029/2000JD000046, 2002.

EEA: Air Quality in Europe - 2015 Report, Tech. rep., https://doi.org/10.2800/62459, 2015.

EEA: Air Quality in Europe - 2017 Report, Tech. rep., https://doi.org/10.2800/850018, 2017.

EMEP: Transboundary particulate matter, photo-oxidants, acidifying and eutrophying components, Tech. rep., MSC-W, CCC and CEIP, 2016.

Emili, E., Lyapustin, A., Wang, Y., Popp, C., Korkin, S., Zebisch, M., Wunderle, S., and Petitta, M.: High spatial resolution aerosol retrieval with MAIAC: Application to mountain regions, J. Geophys. Res., 116, D23211, https://doi.org/10.1029/2011JD016297, 2011.

E-PROFILE: ALC data, available at: http://data.ceda.ac.uk/bade/ eprofile/data/, last access: 7 March 2019.
Estellés, V., Campanelli, M., Smyth, T. J., Utrillas, M. P., and Martínez-Lozano, J. A.: Evaluation of the new ESR network software for the retrieval of direct sun products from CIMEL CE318 and PREDE POM01 sun-sky radiometers, Atmos. Chem. Phys., 12, 11619-11630, https://doi.org/10.5194/acp-12-116192012, 2012.

EU Commission: Directive 2008/50/EC of the European Parliament and of the Council of 21 May 2008 on ambient air quality and cleaner air for Europe, Official Journal of the European Union, L152, 1-44, 2008

EuroSkyRad: Sun-sky radiometer data, available at: http://www. euroskyrad.net/index.html, last access: 7 March 2019.

Federico, S., Torcasio, R. C., Sanò, P., Casella, D., Campanelli, M., Meirink, J. F., Wang, P., Vergari, S., Diémoz, H., and Dietrich, S.: Comparison of hourly surface downwelling solar radiation estimated from MSG-SEVIRI and forecast by the RAMS model with pyranometers over Italy, Atmos. Meas. Tech., 10, 2337 2352, https://doi.org/10.5194/amt-10-2337-2017, 2017.

Fernald, F. G.: Analysis of atmospheric lidar observations: some comments, Appl. Optics, 23, 652-653, https://doi.org/10.1364/AO.23.000652, 1984.

Ferrero, L., Perrone, M. G., Petraccone, S., Sangiorgi, G., Ferrini, B. S., Lo Porto, C., Lazzati, Z., Cocchi, D., Bruno, F., Greco, F., Riccio, A., and Bolzacchini, E.: Vertically-resolved particle size distribution within and above the mixing layer over the Milan metropolitan area, Atmos. Chem. Phys., 10, 3915-3932, https://doi.org/10.5194/acp-10-3915-2010, 2010.

Ferrero, L., Castelli, M., Ferrini, B. S., Moscatelli, M., Perrone, M. G., Sangiorgi, G., D’Angelo, L., Rovelli, G., Moroni, B., Scardazza, F., Mocnik, G., Bolzacchini, E., Petitta, M., and Cappelletti, D.: Impact of black carbon aerosol over Italian basin valleys: high-resolution measurements along vertical profiles, radiative forcing and heating rate, Atmos. Chem. Phys., 14, 96419664, https://doi.org/10.5194/acp-14-9641-2014, 2014.

Ferrero, L., Močnik, G., Cogliati, S., Gregorič, A., Colombo, R., and Bolzacchini, E.: Heating Rate of Light Absorbing Aerosols: Time-Resolved Measurements, the Role of Clouds, and Source Identification, Environ. Sci. Technol., 52, 35463555, https://doi.org/10.1021/acs.est.7b04320, 2018.

Finardi, S. and Pellegrini, U.: Systematic analysis of meteorological conditions causing severe urban air pollution episodes in the central Po Valley, in: 9th Int. Conf. on Harmonisation within Atmospheric Dispersion Modelling for Regulatory Purposes, available at: http://www.harmo.org/Conferences/ proceedings/_Garmisch/publishedSections/6.13.pdf (last access: 28 February 2019), 2004.

Finardi, S., Silibello, C., D'Allura, A., and Radice, P.: Analysis of pollutants exchange between the Po Valley and the surrounding European region, Urban Clim., 10, 682-702, https://doi.org/10.1016/j.uclim.2014.02.002, 2014.

Freney, E. J., Sellegri, K., Canonaco, F., Boulon, J., Hervo, M., Weigel, R., Pichon, J. M., Colomb, A., Prévt^, A. S. H., and Laj, P.: Seasonal variations in aerosol particle composition at the puy-de-Dôme research station in France, Atmos. Chem. Phys., 11, 13047-13059, https://doi.org/10.5194/acp-11-130472011, 2011.

Fuzzi, S., Baltensperger, U., Carslaw, K., Decesari, S., Denier van der Gon, H., Facchini, M. C., Fowler, D., Koren, I., Langford, B., Lohmann, U., Nemitz, E., Pandis, S., Riipinen, I., Rudich, 
Y., Schaap, M., Slowik, J. G., Spracklen, D. V., Vignati, E., Wild, M., Williams, M., and Gilardoni, S.: Particulate matter, air quality and climate: lessons learned and future needs, Atmos. Chem. Phys., 15, 8217-8299, https://doi.org/10.5194/acp15-8217-2015, 2015.

Gariazzo, C., Silibello, C., Finardi, S., Radice, P., Piersanti, A., Calori, G., Cecinato, A., Perrino, C., Nussio, F., Cagnoli, M., Pelliccioni, A., Gobbi, G. P., and Di Filippo, P.: A gas/aerosol air pollutants study over the urban area of Rome using a comprehensive chemical transport model, Atmos. Environ., 41, 7286-7303, https://doi.org/10.1016/j.atmosenv.2007.05.018, 2007.

Gilardoni, S., Massoli, P., Giulianelli, L., Rinaldi, M., Paglione, M., Pollini, F., Lanconelli, C., Poluzzi, V., Carbone, S., Hillamo, R., Russell, L. M., Facchini, M. C., and Fuzzi, S.: Fog scavenging of organic and inorganic aerosol in the Po Valley, Atmos. Chem. Phys., 14, 6967-6981, https://doi.org/10.5194/acp14-6967-2014, 2014.

Gilardoni, S., Massoli, P., Paglione, M., Giulianelli, L., Carbone, C., Rinaldi, M., Decesari, S., Sandrini, S., Costabile, F., Gobbi, G. P., Pietrogrande, M. C., Visentin, M., Scotto, F., Fuzzi, S., and Facchini, M. C.: Direct observation of aqueous secondary organic aerosol from biomassburning emissions, P. Natl. Acad. Sci. USA, 113, 10013-10018, https://doi.org/10.1073/pnas.1602212113, 2016.

Gohm, A., Harnisch, F., Vergeiner, J., Obleitner, F., Schnitzhofer, R., Hansel, A., Fix, A., Neininger, B., Emeis, S., and Schäfer, K.: Air Pollution Transport in an Alpine Valley: Results From Airborne and Ground-Based Observations, Bound.-Lay. Meteorol., 131, 441-463, https://doi.org/10.1007/s10546-009-9371-9, 2009.

Green, D. C., Fuller, G. W., and Baker, T.: Development and validation of the volatile correction model for $\mathrm{PM}_{10}$ - An empirical method for adjusting TEOM measurements for their loss of volatile particulate matter, Atmos. Environ., 43, 2132-2141, https://doi.org/10.1016/j.atmosenv.2009.01.024, 2009.

Guariso, G. and Volta, M.: Air Quality Integrated Assessment: A European Perspective, Springer, https://doi.org/10.1007/978-3319-33349-6, 2017.

Haeffelin, M., Angelini, F., Morille, Y., Martucci, G., Frey, S., Gobbi, G. P., Lolli, S., O’Dowd, C. D., Sauvage, L., XuerefRémy, I., Wastine, B., and Feist, D. G.: Evaluation of MixingHeight Retrievals from Automatic Profiling Lidars and Ceilometers in View of Future Integrated Networks in Europe, Bound.Lay. Meteorol., 143, 49-75, https://doi.org/10.1007/s10546-0119643-z, 2012.

Henne, S., Furger, M., Nyeki, S., Steinbacher, M., Neininger, B., de Wekker, S. F. J., Dommen, J., Spichtinger, N., Stohl, A., and Prévôt, A. S. H.: Quantification of topographic venting of boundary layer air to the free troposphere, Atmos. Chem. Phys., 4, 497509, https://doi.org/10.5194/acp-4-497-2004, 2004.

Henne, S., Furger, M., and Prévôt, A. S. H.: Climatology of Mountain Venting-Induced Elevated Moisture Layers in the Lee of the Alps, J. Appl. Meteorol., 44, 620-633, https://doi.org/10.1175/JAM2217.1, 2005.

Kambezidis, H. and Kaskaoutis, D.: Aerosol climatology over four AERONET sites: An overview, Atmos. Environ., 42, 1892-1906, https://doi.org/10.1016/j.atmosenv.2007.11.013, 2008.
Kaufman, Y. and Tanré, D.: Algorithm for remote sensing of tropospheric aerosol form MODIS, MODIS ATBD MOD02, 9, 1-85, Tech. rep., 1998.

Kazadzis, S., Kouremeti, N., Diémoz, H., Gröbner, J., Forgan, B. W., Campanelli, M., Estellés, V., Lantz, K., Michalsky, J., Carlund, T., Cuevas, E., Toledano, C., Becker, R., Nyeki, S., Kosmopoulos, P. G., Tatsiankou, V., Vuilleumier, L., Denn, F. M., Ohkawara, N., Ijima, O., Goloub, P., Raptis, P. I., Milner, M., Behrens, K., Barreto, A., Martucci, G., Hall, E., Wendell, J., Fabbri, B. E., and Wehrli, C.: Results from the Fourth WMO Filter Radiometer Comparison for aerosol optical depth measurements, Atmos. Chem. Phys., 18, 3185-3201, https://doi.org/10.5194/acp-18-3185-2018, 2018.

Khan, M., Masiol, M., Formenton, G., Di Gilio, A., de Gennaro, G., Agostinelli, C., and Pavoni, B.: Carbonaceous $\mathrm{PM}_{2.5}$ and secondary organic aerosol across the Veneto region (NE Italy), Sci. Total Environ., 542, 172-181, https://doi.org/10.1016/j.scitotenv.2015.10.103, 2016.

Khatri, P. and Takamura, T.: An Algorithm to Screen CloudAffected Data for Sky Radiometer Data Analysis, J. Meteorol. Soc. Jpn., 87, 189-204, https://doi.org/10.2151/jmsj.87.189, 2009.

Kim, H., Zhang, Q., and Heo, J.: Influence of intense secondary aerosol formation and long-range transport on aerosol chemistry and properties in the Seoul Metropolitan Area during spring time: results from KORUS-AQ, Atmos. Chem. Phys., 18, 71497168, https://doi.org/10.5194/acp-18-7149-2018, 2018.

Klett, J. D.: Lidar inversion with variable backscatter/extinction ratios, Appl. Optics, 24, 1638-1643, https://doi.org/10.1364/AO.24.001638, 1985.

Lang, M. N., Gohm, A., and Wagner, J. S.: The impact of embedded valleys on daytime pollution transport over a mountain range, Atmos. Chem. Phys., 15, 11981-11998, https://doi.org/10.5194/acp-15-11981-2015, 2015.

Larsen, B., Gilardoni, S., Stenström, K., Niedzialek, J., Jimenez, J., and Belis, C.: Sources for PM air pollution in the Po Plain, Italy: II. Probabilistic uncertainty characterization and sensitivity analysis of secondary and primary sources, Atmos. Environ., 50, 203-213, https://doi.org/10.1016/j.atmosenv.2011.12.038, 2012.

Lau, W. K., Kim, M.-K., Kim, K.-M., and Lee, W.-S.: Enhanced surface warming and accelerated snow melt in the Himalayas and Tibetan Plateau induced by absorbing aerosols, Environ. Res. Lett., 5, 025204, https://doi.org/10.1088/1748-9326/5/2/025204, 2010.

Lehner, M. and Rotach, M. W.: Current Challenges in Understanding and Predicting Transport and Exchange in the Atmosphere over Mountainous Terrain, Atmosphere, 9, 276, https://doi.org/10.3390/atmos9070276, 2018.

Lim, Y. B., Seo, J., Kim, J. Y., and Turpin, B. J.: Multiday haze in the East Asia: Transport and chemical aging of hygroscopic particles, Atmos. Chem. Phys. Discuss., https://doi.org/10.5194/acp-2018-364, 2018.

Lyapustin, A., Wang, Y., Laszlo, I., Kahn, R., Korkin, S., Remer, L., Levy, R., and Reid, J. S.: Multiangle implementation of atmospheric correction (MAIAC): 2. Aerosol algorithm, J. Geophys. Res., 116, D03211, https://doi.org/10.1029/2010JD014986, 2011.

Lyapustin, A., Wang, Y., Laszlo, I., and Korkin, S.: Improved cloud and snow screening in MAIAC aerosol retrievals using 
spectral and spatial analysis, Atmos. Meas. Tech., 5, 843-850, https://doi.org/10.5194/amt-5-843-2012, 2012.

Manara, V., Bassi, M., Brunetti, M., Cagnazzi, B., and Maugeri, M.: 1990-2016 surface solar radiation variability and trend over the Piedmont region (northwest Italy), Theor. Appl. Climatol., https://doi.org/10.1007/s00704-018-2521-6, 2018.

Mélin, F. and Zibordi, G.: Aerosol variability in the Po Valley analyzed from automated optical measurements, Geophy. Res. Lett., 32, L03810, https://doi.org/10.1029/2004GL021787, 2005.

Mercalli, L., Castellano, C., Cat Berro, D., and Di Napoli, G.: Atlante climatico della Valle d'Aosta, vol. 2, Società Meteorologica Subalpina, 2003.

Moroni, B., Castellini, S., Crocchianti, S., Piazzalunga, A., Fermo, P., Scardazza, F., and Cappelletti, D.: Ground-based measurements of long-range transported aerosol at the rural regional background site of Monte Martano (Central Italy), Atmos. Res., 155, 26-36, https://doi.org/10.1016/j.atmosres.2014.11.021, 2015.

Nakajima, T., Tonna, G., Rao, R., Boi, P., Kaufman, Y., and Holben, B.: Use of sky brightness measurements from ground for remote sensing of particulate polydispersions, Appl. Optics, 35, 26722686, https://doi.org/10.1364/AO.35.002672, 1996.

Neftel, A., Spirig, C., Prévôt, A. S. H., Furger, M., Stutz, J., Vogel, B., and Hjorth, J.: Sensitivity of photooxidant production in the Milan Basin: An overview of results from a EUROTRAC-2 Limitation of Oxidant Production field experiment, J. Geophys. Res., 107, LOP 1-1-LOP 1-10, https://doi.org/10.1029/2001JD001263, 2002.

Nenes, A., Pandis, S. N., and Pilinis, C.: ISORROPIA: A new thermodynamic equilibrium model for multiphase multicomponent inorganic aerosols, Aquat. Geochem., 4, 123-152, https://doi.org/10.1023/A:1009604003981, 1998.

Nyeki, S., Eleftheriadis, K., Baltensperger, U., Colbeck, I., Fiebig, M., Fix, A., Kiemle, C., Lazaridis, M., and Petzold, A.: Airborne Lidar and in-situ Aerosol Observations of an Elevated Layer, Leeward of the European Alps and Apennines, Geophys. Res. Lett., 29, 33-1-33-4, https://doi.org/10.1029/2002GL014897, 2002.

Osborne, S. R., Haywood, J. M., and Bellouin, N.: In situ and remote-sensing measurements of the mean microphysical and optical properties of industrial pollution aerosol during ADRIEX, Q. J. Roy. Meteor. Soc., 133, 17-32, https://doi.org/10.1002/qj.92, 2007.

Patashnick, H. and Rupprecht, E. G.: Continuous PM-10 Measurements Using the Tapered Element Oscillating Microbalance, J. Air Waste Manage., 41, 1079-1083, https://doi.org/10.1080/10473289.1991.10466903, 1991.

Pletscher, K., Weiss, M., and Moelter, L.: Simultaneous determination of PM fractions, particle number and particle size distribution in high time resolution applying one and the same optical measurement technique, Gefahrst. Reinhalt. L., 76, 425-436, 2016.

Putaud, J.-P., Dingenen, R. V., Alastuey, A., Bauer, H., Birmili, W., Cyrys, J., Flentje, H., Fuzzi, S., Gehrig, R., Hansson, H., Harrison, R., Herrmann, H., Hitzenberger, R., Häglin, C., Jones, A., Kasper-Giebl, A., Kiss, G., Kousa, A., Kuhlbusch, T., Löschau, G., Maenhaut, W., Molnar, A., Moreno, T., Pekkanen, J., Perrino, C., Pitz, M., Puxbaum, H., Querol, X., Rodriguez, S., Salma, I., Schwarz, J., Smolik, J., Schneider, J., Spindler, G., ten Brink,
H., Tursic, J., Viana, M., Wiedensohler, A., and Raes, F.: A European aerosol phenomenology - 3: Physical and chemical characteristics of particulate matter from 60 rural, urban, and kerbside sites across Europe, Atmos. Environ., 44, 1308-1320, https://doi.org/10.1016/j.atmosenv.2009.12.011, 2010.

Rampanelli, G., Zardi, D., and Rotunno, R.: Mechanisms of Up-Valley Winds, J. Atmos. Sci., 61, 3097-3111, https://doi.org/10.1175/JAS-3354.1, 2004.

Raut, J.-C. and Chazette, P.: Assessment of vertically-resolved $\mathrm{PM}_{10}$ from mobile lidar observations, Atmos. Chem. Phys., 9, 8617-8638, https://doi.org/10.5194/acp-9-8617-2009, 2009.

Remer, L. A., Mattoo, S., Levy, R. C., and Munchak, L. A.: MODIS $3 \mathrm{~km}$ aerosol product: algorithm and global perspective, Atmos. Meas. Tech., 6, 1829-1844, https://doi.org/10.5194/amt-6-18292013, 2013.

Rosati, B., Gysel, M., Rubach, F., Mentel, T. F., Goger, B., Poulain, L., Schlag, P., Miettinen, P., Pajunoja, A., Virtanen, A., Klein Baltink, H., Henzing, J. S. B., Größ, J., Gobbi, G. P., Wiedensohler, A., Kiendler-Scharr, A., Decesari, S., Facchini, M. C., Weingartner, E., and Baltensperger, U.: Vertical profiling of aerosol hygroscopic properties in the planetary boundary layer during the PEGASOS campaigns, Atmos. Chem. Phys., 16, 7295-7315, https://doi.org/10.5194/acp-16-7295-2016, 2016.

Saarikoski, S., Carbone, S., Decesari, S., Giulianelli, L., Angelini, F., Canagaratna, M., Ng, N. L., Trimborn, A., Facchini, M. C., Fuzzi, S., Hillamo, R., and Worsnop, D.: Chemical characterization of springtime submicrometer aerosol in Po Valley, Italy, Atmos. Chem. Phys., 12, 8401-8421, https://doi.org/10.5194/acp12-8401-2012, 2012.

Schaap, M., van Loon, M., ten Brink, H. M., Dentener, F. J., and Builtjes, P. J. H.: Secondary inorganic aerosol simulations for Europe with special attention to nitrate, Atmos. Chem. Phys., 4, 857-874, https://doi.org/10.5194/acp-4-857-2004, 2004.

Schmidli, J.: Daytime Heat Transfer Processes over Mountainous Terrain, J. Atmos. Sci., 70, 4041-4066, https://doi.org/10.1175/JAS-D-13-083.1, 2013.

Schnitzhofer, R., Norman, M., Wisthaler, A., Vergeiner, J., Harnisch, F., Gohm, A., Obleitner, F., Fix, A., Neininger, B., and Hansel, A.: A multimethodological approach to study the spatial distribution of air pollution in an Alpine valley during wintertime, Atmos. Chem. Phys., 9, 3385-3396, https://doi.org/10.5194/acp-9-3385-2009, 2009.

Serafin, S. and Zardi, D.: Daytime Heat Transfer Processes Related to Slope Flows and Turbulent Convection in an Idealized Mountain Valley, J. Atmos. Sci., 67, 3739-3756, https://doi.org/10.1175/2010JAS3428.1, 2010.

Serafin, S., Adler, B., Cuxart, J., De Wekker, S. F. J., Gohm, A., Grisogono, B., Kalthoff, N., Kirshbaum, D. J., Rotach, M. W., Schmidli, J., Stiperski, I., Večenaj, Ž., and Zardi, D.: Exchange Processes in the Atmospheric Boundary Layer Over Mountainous Terrain, Atmosphere, 9, 102, https://doi.org/10.3390/atmos9030102, 2018.

Siani, A. M., Modesti, S., Casale, G. R., Diémoz, H., and Colosimo, A.: Biologically effective surface UV climatology at Rome and Aosta, Italy, AIP Conf. Proc., 1531, 903-906, https://doi.org/10.1063/1.4804917, 2013.

Siani, A. M., Frasca, F., Scarlatti, F., Religi, A., Diémoz, H., Casale, G. R., Pedone, M., and Savastiouk, V.: Examination on total ozone column retrievals by Brewer spectrophotometry using dif- 
ferent processing software, Atmos. Meas. Tech., 11, 5105-5123, https://doi.org/10.5194/amt-11-5105-2018, 2018.

Silibello, C., Calori, G., Brusasca, G., Giudici, A., Angelino, E., Fossati, G., Peroni, E., and Buganza, E.: Modelling of $\mathrm{PM}_{10}$ concentrations over Milano urban area using two aerosol modules, Environ. Modell. Softw., 23, 333-343, https://doi.org/10.1016/j.envsoft.2007.04.002, 2008.

Sokhi, R., Kitwiroon, N., and Luhana, L.: FUMAPEX Datasets of Urban Air Pollution Models and Meteorological Preprocessors, in: Fumapex Report D, vol. 2, 1-D2, 2003.

Sprenger, M. and Wernli, H.: The LAGRANTO Lagrangian analysis tool - version 2.0, Geosci. Model Dev., 8, 2569-2586, https://doi.org/10.5194/gmd-8-2569-2015, 2015.

Straif, K., Cohen, A., and Samet, J. (Eds.): Air pollution and cancer, WHO Press, World Health Organization, 2013.

Tampieri, F., Trombetti, F., and Scarani, C.: Summer daily circulation in the Po Valley, Italy, Geophys. Astro. Fluid, 17, 97-112, https://doi.org/10.1080/03091928108243675, 1981.

Thyer, N. H.: A theoretical explanation of mountain and valley winds by a numerical method, Archiv für Meteorologie, Geophysik und Bioklimatologie, Serie A, 15, 318-348, https://doi.org/10.1007/BF02247220, 1966.

Turpin, B. J. and Lim, H.-J.: Species Contributions to $\mathrm{PM}_{2.5}$ Mass Concentrations: Revisiting Common Assumptions for Estimating Organic Mass, Aerosol Sci. Tech., 35, 602-610, https://doi.org/10.1080/02786820152051454, 2001.

Uchino, O., Sakai, T., Izumi, T., Nagai, T., Morino, I., Yamazaki, A., Deushi, M., Yumimoto, K., Maki, T., Tanaka, T. Y., Akaho, T., Okumura, H., Arai, K., Nakatsuru, T., Matsunaga, T., and Yokota, T.: Lidar detection of high concentrations of ozone and aerosol transported from northeastern Asia over Saga, Japan, Atmos. Chem. Phys., 17, 1865-1879, https://doi.org/10.5194/acp17-1865-2017, 2017.

Van Donkelaar, A., Martin, R. V., Brauer, M., Kahn, R., Levy, R., Verduzco, C., and Villeneuve, P. J.: Global estimates of ambient fine particulate matter concentrations from satellite-based aerosol optical depth: development and application, Environ. Health Persp., 118, 847, https://doi.org/10.1289/ehp.0901623, 2010.

Vuillermoz, M., Berlier, F., Borlino, M. C., Crea, D., Tartin, C., and Tibone, C.: Influence of vertical temperature gradients on outdoor sound propagation in a narrow valley, in: AIA-DAGA 2013 proceedings of the International Conference on Acoustics, 1821 March 2013, Merano, Italy, 2013.

Wagner, J. S., Gohm, A., and Rotach, M. W.: The impact of valley geometry on daytime thermally driven flows and vertical transport processes, Q. J. Roy. Meteor. Soc., 141, 1780-1794, https://doi.org/10.1002/qj.2481, 2014
Weissmann, M., Braun, F. J., Gantner, L., Mayr, G. J., Rahm, S., and Reitebuch, O.: The Alpine Mountain-Plain Circulation: Airborne Doppler Lidar Measurements and $\mathrm{Nu}-$ merical Simulations, Mon. Weather Rev., 133, 3095-3109, https://doi.org/10.1175/MWR3012.1, 2005.

WHO: Ambient air pollution: a global assessment of exposure and burden of disease, Tech. rep., 2016.

Wiegner, M. and Gasteiger, J.: Correction of water vapor absorption for aerosol remote sensing with ceilometers, Atmos. Meas. Tech., 8, 3971-3984, https://doi.org/10.5194/amt-8-3971-2015, 2015.

Wiegner, M. and Geiß, A.: Aerosol profiling with the Jenoptik ceilometer CHM15kx, Atmos. Meas. Tech., 5, 1953-1964, https://doi.org/10.5194/amt-5-1953-2012, 2012.

WMO: WMO/IGAC Impacts of megacities on air pollution and climate, Tech. rep., World Meteorological Organization, available at: https://library.wmo.int/pmb_ged/gaw_205.pdf (last access: 28 February 2019), 2012.

Wotawa, G., Kröger, H., and Stohl, A.: Transport of ozone towards the Alps - results from trajectory analyses and photochemical model studies, Atmos. Environ., 34, 1367-1377, https://doi.org/10.1016/S1352-2310(99)00363-5, 2000.

Wyngaard, J. C.: Toward Numerical Modeling in the "Terra Incognita", J. Atmos. Sci., 61, 1816-1826, https://doi.org/10.1175/15200469(2004)061<1816:TNMITT>2.0.CO;2, 2004.

Zeng, Z., Chen, A., Ciais, P., Li, Y., Li, L. Z. X., Vautard, R., Zhou, L., Yang, H., Huang, M., and Piao, S.: Regional air pollution brightening reverses the greenhouse gases induced warming-elevation relationship, Geophys. Res. Lett., 42, 45634572, https://doi.org/10.1002/2015GL064410, 2015.

Zhang, Q., Jiang, X., Tong, D., Davis, S. J., Zhao, H., Geng, G., Feng, T., Zheng, B., Lu, Z., Streets, D. G., Ni, R., Brauer, M., van Donkelaar, A., Martin, R. V., Huo, H., Liu, Z., Pan, D., Kan, H., Yan, Y., Lin, J., He, K., and Guan, D.: Transboundary health impacts of transported global air pollution and international trade, Nature, 543, 705-709, https://doi.org/10.1038/nature21712, 2017.

Zuev, V. V., Burlakov, V. D., Nevzorov, A. V., Pravdin, V. L., Savelieva, E. S., and Gerasimov, V. V.: 30-year lidar observations of the stratospheric aerosol layer state over Tomsk (Western Siberia, Russia), Atmos. Chem. Phys., 17, 3067-3081, https://doi.org/10.5194/acp-17-3067-2017, 2017. 